\title{
Assessment of landslide-induced damage to structures: the Agnone landslide case study (southern Italy)
}

\author{
Matteo Del Soldato ${ }^{1}$ (D) Diego Di Martire ${ }^{2} \cdot$ Silvia Bianchini $^{1} \cdot$ Roberto Tomás $^{3} \cdot$ Pantaleone De Vita $^{2}$. \\ Massimo Ramondini ${ }^{4} \cdot$ Nicola Casagli $^{1}$ • Domenico Calcaterra ${ }^{2}$
}

Received: 3 November 2017 / Accepted: 30 April 2018 / Published online: 30 May 2018

(C) The Author(s) 2018

\begin{abstract}
Landslides are among the most important and frequent natural calamities that cause severe socio-economic and human losses. After earthquakes, landslides are responsible for the greatest number of casualties and the largest amount of damage to man-made structures. On average, southern Italy is affected by a high spatial density of landslides due to its complex geological setting, which often predisposes it to slope instability phenomena under both natural and anthropogenic influences. Structurally complex formations are widespread in the southern Apennines and are characterized by high heterogeneity and very poor mechanical properties. Thus, these formations represent one of the main factors contributing to the predisposition of slopes to landsliding. In this paper, landslide-induced damage was investigated and analyzed in an area within the municipality of Agnone (Molise region), which is affected by a complex landslide that involves a structurally complex formation. The approaches used were based on six different methods that have previously been described in the literature, and a comparison of the results was made. Data regarding the damage, which consists largely of cracks observed in buildings and at the ground, were compiled through field surveys. The results were critically analyzed to note the advantages and constraints of each classification scheme. The aim of the work was to apply and compare different approaches in order to test the best and most accurate procedures for assessing damage due to landslides at the scale of individual buildings as well as to provide an objective assessment of the degree of landslide damage to structures and facilities.
\end{abstract}

Keywords Landslides $\cdot$ Structurally complex formations $\cdot$ Damage classification $\cdot$ Buildings $\cdot$ Agnone

\section{Introduction}

Landslides are gravity-controlled natural or anthropogenic processes that represent the most widespread geological hazard worldwide (Schuster 1996; Schuster and Highland 2001). They have potentially catastrophic effects and cause considerable socio-economic damage as well as fatalities. Mass movements are caused by several predisposing and

\footnotetext{
Matteo Del Soldato

matteo.delsoldato@unifi.it

Diego Di Martire

diego.dimartire@unina.it

Silvia Bianchini

silvia.bianchini@unifi.it

Roberto Tomás

roberto.tomas@ua.es

Pantaleone De Vita

pantaleona.devita@unina.it

Massimo Ramondini

massimo.ramondini@unina.it
}

\author{
Nicola Casagli \\ nicola.casagli@unifi.it \\ Domenico Calcaterra \\ domenico.calcaterra@unina.it
}

1 Earth Sciences Department, University of Florence, Via La Pira 4, 50121 Florence, Italy

2 Department of Earth Sciences, Environment and Resources, University of Naples Federico II, Largo San Marcellino 10, 80138 Naples, Italy

3 Departamento de Ingeniería Civil, University of Alicante, P.O. Box 99, E-03080 Alicante, Spain

4 Department of Civil, Architectural and Environmental Engineering, Federico II University of Naples, via Claudio 21, 80125 Naples, Italy 
driving factors, including both natural and anthropogenic factors, such as deforestation or poor urban planning. Anthropogenic factors are locally worse than natural ones (Wu and Qiao 2009; Di Martire et al. 2012; Tofani et al. 2013; Wu et al. 2015).

In Italy, population growth and the consequent expansion of urban areas (Rybár 1997) have often induced people to build structures in areas over dormant landslides or at the edges of active landslide areas. Moreover, the disregard of the laws countervailed with several successive amnesties because of infringement, in addition to the loss of memory of past ruinous landslide events, have led to the development of facilities in hazardous areas, such as volcanic- or landslideprone regions. Urban expansion can cause modifications to hillslope morphology, inducing terrain remobilization and reactivation of old landslides that were previously dormant or suspended, despite thousands of years of knowledge of negative experiences (Chiocchio et al. 1997).

Physical vulnerability, which defines the level of damage to critical infrastructures and buildings, is a key parameter in risk assessment. The occurrence of several landslides in urban areas has highlighted the need to create a standard procedure to recognize and classify different levels of damage in order to help land management authorities (Alexander 1986) to focus and carry out mitigation strategies. Slope movements cause damage to buildings and other facilities and impose direct (e.g., replacement, repair or maintenance of damaged structures) and indirect costs (all other costs, which are difficult to evaluate, e.g., losses of service) (Schuster and Fleming 1986; Schuster 1996; Godt et al. 2000). These costs depend on several factors, including the dimensions and velocity of the mass movement, the magnitude and type of the landslide mechanism, the lithology involved, the morphological features, and the effects of anthropogenic activity.

Attention is usually paid to planning strategies to prevent or reduce urban landslide disasters, rather than evaluating their impacts and the resulting damage. Maps illustrating the level of damage to affected buildings could provide an instrument to prevent the construction of facilities in historically landslide-prone areas. Furthermore, mountainous and geologically complex environments characterized by the presence of structurally complex formations (Esu 1977), such as the southern Apennines, and associated with intense or prolonged rainfall events, or to strong seismic shocks, are usually very prone to landslides.

This work addresses the description and classification of buildings and facilities damaged by the reactivation of a slow-moving and intermittent landslide, known from the beginning of the XIX century, using six different damage assessment approaches. The landslide is located in the municipality of Agnone (Molise region, southern Italy), occurred in 2003, and involves Miocene-Pliocene clayey-marl lithologies.
The level of damage was assessed by means of different existing methods developed in various contexts and for different purposes. (i) The first method is based on the rehabilitation of the observable cracks (Burland 1977; Boscardin and Cording 1989); (ii) the second method was developed after an important landslide event in Italy (Alexander 1986); (iii) the third is focused on the survey of damage to buildings in landslide-affected areas (Chiocchio et al. 1997); (iv) the fourth approach is a scheme realized by merging several damage classifications for use with subsidence, mining-related, and landslip events (Cooper 2008); (v) the fifth method (Baggio et al. 2009) was proposed for post-seismic events by the Italian Department of Civil Protection (DPC hereafter); and (vi) the sixth method is a recently published approach based on the previous ones and was developed in two subsequent phases to assess the severity of cracks and constructions (Del Soldato et al. 2017). Landslide-induced damages at the study site were recorded and assessed by means of two field surveys conducted in November 2015 and in July 2016.

The main aim of this work is to apply and compare different methods for classifying landslide-induced damage on structures and facilities in order to evaluate the most accurate field procedure for the management and adoption of prevention and remedial measures through a landslide case study in Agnone, Italy. The main advantages and drawbacks of the different classifications are analyzed and discussed.

The paper is structured as follows: the next section briefly describes the geological and geomorphological setting of the Colle Lapponi - Piano Ovetta (CL-PO) landslide-prone area. The presentation details of the different damage assessment approaches applied for the categorization of the buildings and infrastructures are given after that. Then the details of the field work developed for the classification of the damage and the recognized landslide-induced damage are described. Followed by a discussion of the main results obtained by applying the six methods. Finally, the main conclusions of the paper are summarized.

\section{Geological and geomorphological setting}

The study area (Fig. 1a) is sited in the western part of the municipality of Agnone (Molise, southern Italy) and is strongly affected by landslides and erosional processes. The CL-PO area is located in the catchment of the San Nicola Valley, a sub-basin on the hydrographic right side of the Verrino Torrent.

The outcropping geological units include the Upper Miocene Agnone flysch (Sannitico-Molisane Formations) (Vezzani et al. 2004, Fig. 1b). This is characterized by 


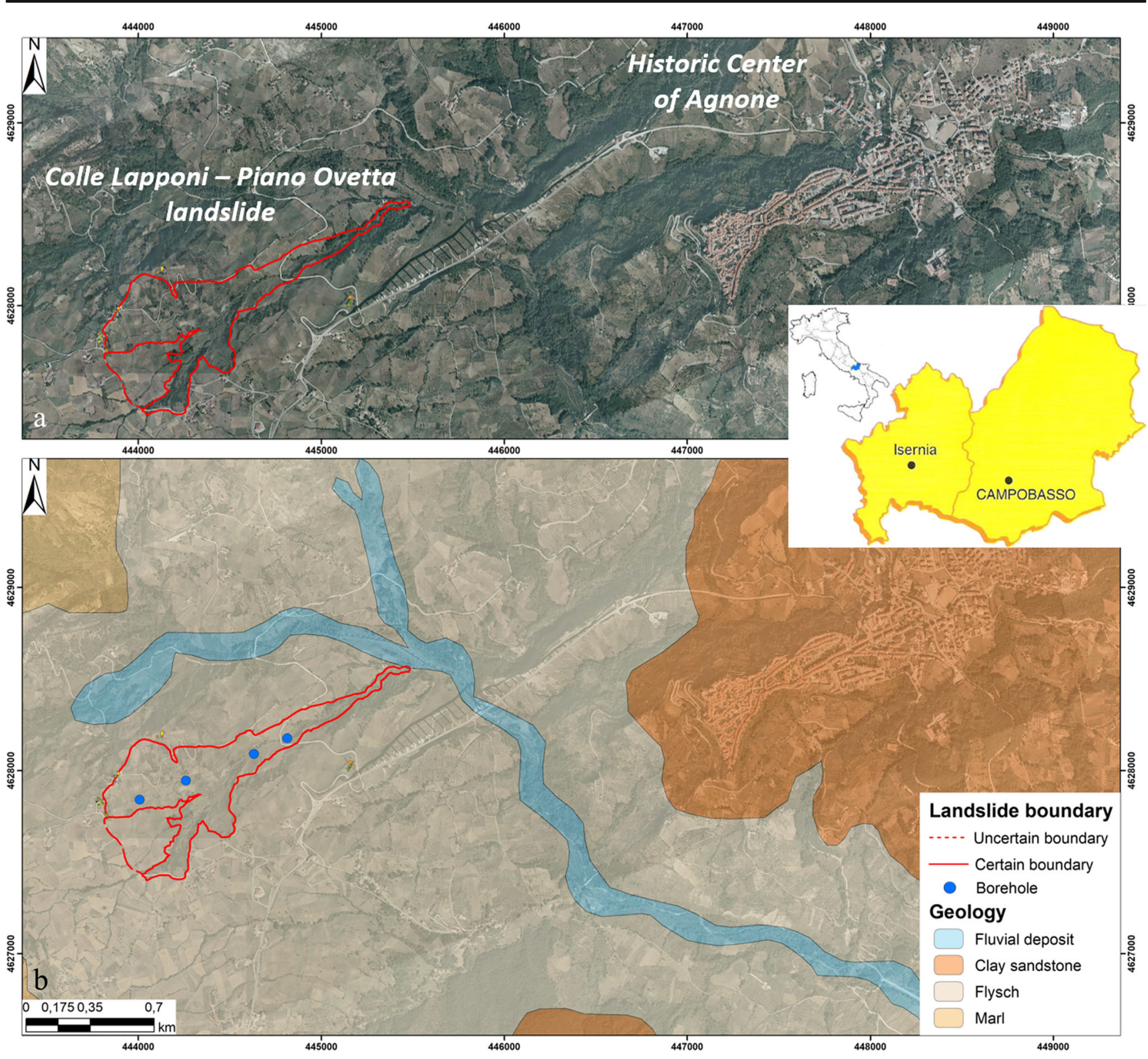

Fig. 1 Location of the area of interest (a). Geological sketch map of the region of Molise (Vezzani et al. 2004) (b). The red line is the outline of the CL-PO landslide

turbiditic siliciclastic deposits composed of alternating thin layers of clayey sandstones, sandstones, and arenites (Filocamo et al. 2015). The CL-PO landslide involves the upper member of the Agnone flysch, which is made up of marl, clayey, and subordinate grayish sandy levels with low mechanical resistance and some alterations. Some lithic intercalations, consisting of sandstone or calcareous levels with highly variable thicknesses, are also present. The Agnone Formation is covered by a superficial regolith horizon composed of clay, silty clay, and occasional sand with diffuse alteration traces, abundant organic material, and some clasts.

Calcaterra et al. (2008) performed a geotechnical characterization of the landslide by means of several geological and geotechnical campaigns in which four boreholes were drilled. They recognized four distinct layers (Fig. 2), described from top to bottom as follows:

Level A - hard rock and mudstone fragments distributed throughout a chaotic and plastic clay matrix. Direct shear tests performed on matrix samples indicated a peak friction angle of approximately $19^{\circ}$ and a cohesion of $20 \mathrm{kPa}$. This horizon was directly involved in the 2003 reactivation of the CL-PO landslide;

Level B - gray clay, silty clay, sandy clay, and silty sand. This layer displays medium plasticity and has a drained peak friction angle near $23^{\circ}$ and a drained cohesion of approximately $28 \mathrm{kPa}$; 
Fig. 2 Engineering geological cross section passing through the median axis of the landslide with the locations of boreholes $\mathrm{S} 1, \mathrm{~S} 2$, $\mathrm{S} 3$, and S4 modified from Calcaterra et al. (2008). A - hard rock fragments and clays; $\mathrm{B}$ clays and sands; $\mathrm{C}$ - limestone level; D - marls and clays

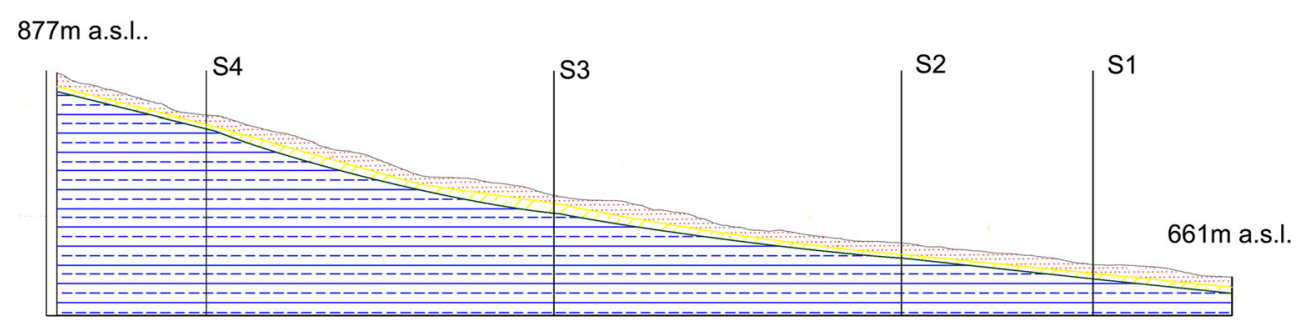

$\mathrm{L}=1245 \mathrm{~m}$

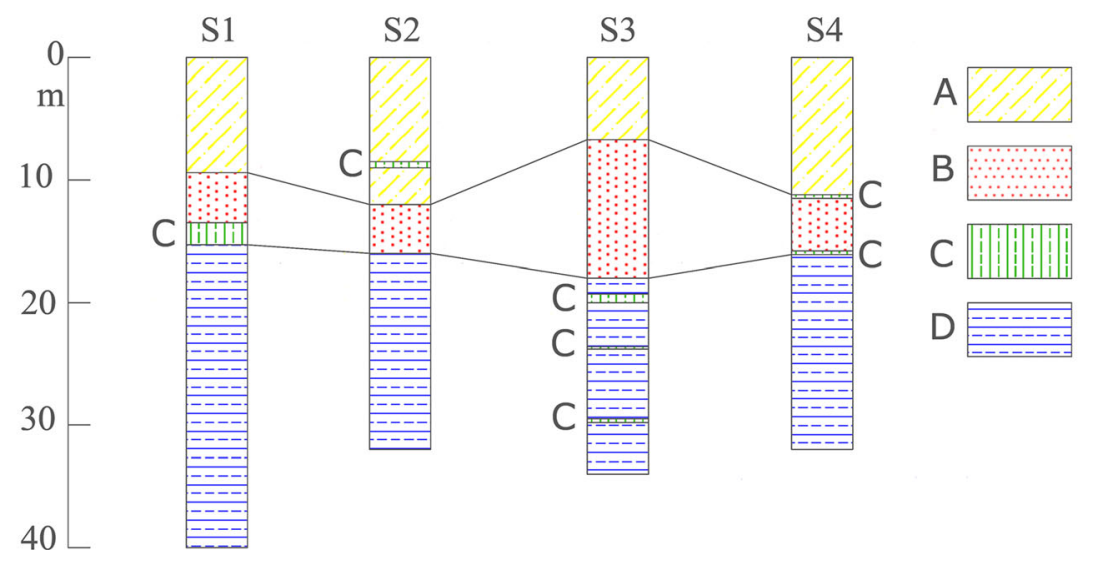

Level C - calcareous levels with thicknesses varying from 0.1 to $1.0 \mathrm{~m}$;

Level D - marly clays, marls, and clayey marls with silt and clay fractions. This horizon exhibits a plasticity comparable to that of level B but with a drained peak friction angle close to $22^{\circ}$ and a drained cohesion of approximately $60 \mathrm{kPa}$.

The main sliding surface is located at a depth of approximately $25 \mathrm{~m}$ in the upper and central part of the landslide. The depth of the surface of rupture considerably decreases in the lower portion of the landslide, in which the movement seems to evolve into an earth flow up to a few meters thick. Weathering effects, which consist of discolored, decomposed, and weakened hard rocks, as well as scaly structures, were recognized in the borehole logs. An intercalation of fractured and highly permeable calcareous beds, with thicknesses ranging from decimeters to one meter, were observed (Calcaterra et al. 2008).

The ground morphology is controlled by the outcropping lithotypes. Calcareous slopes show the highest gradients (close to $30-35^{\circ}$ ), whereas the argillaceous flysch units exhibit slope gradients of approximately $5-10^{\circ}$. In areas where erosional processes are more significant, the steepness increases to $15-20^{\circ}$. The 2003 CL-PO landslide developed along a slope sector that lies between 850 and $650 \mathrm{~m}$ a.s.l. and has a length of approximately $1500 \mathrm{~m}$ down to the confluence with the Verrino Torrent at $590 \mathrm{~m}$ a.s.l. The entire landslide area has an average slope of approximately $10^{\circ}$ with peak values in the upper portion reaching $30^{\circ}$.
The climate of the region is temperate with temperatures ranging from 0 to $27^{\circ} \mathrm{C}$ in winter and summer, respectively. Precipitation falls primarily during the rainy period from September to April with an average monthly accumulation approximately of $80 \mathrm{~mm}$ to which the snow must be added. During the summer season (from July to August) the accumulated rainfall is approximately $45 \mathrm{~mm}$ (http://www.regione. molise.it/schemiidrici). The morphology of the area has changed constantly over time as the reshaping of the earth surface has progressed due to the evolutionary stages of the landslide (Fig. 3). After the reactivation occurred in 2003, an important standing water body was identified in the middle portion of the landslide. This area is delimited by an important scarp and a counterslope, upstream and downstream, respectively, due to the geometry of the mass movement. The morphology of the area is flatter due to drainage works and the deposition of sediments transported by the surface runoff. Other scarps that have been smoothed by erosional processes are clearly recognizable within the landslide area. These scarps are located close to both flanks, as well as in the central and upper portion of the body of the mass movement. The recognizable ground surface fractures were considered in the classification as a relevant element for analysis of the extension and evolution of the gravitational phenomenon.

\section{Overview of the landslide inventory at Agnone}

The availability of historical data, including information regarding localization and triggering factors, allows the 

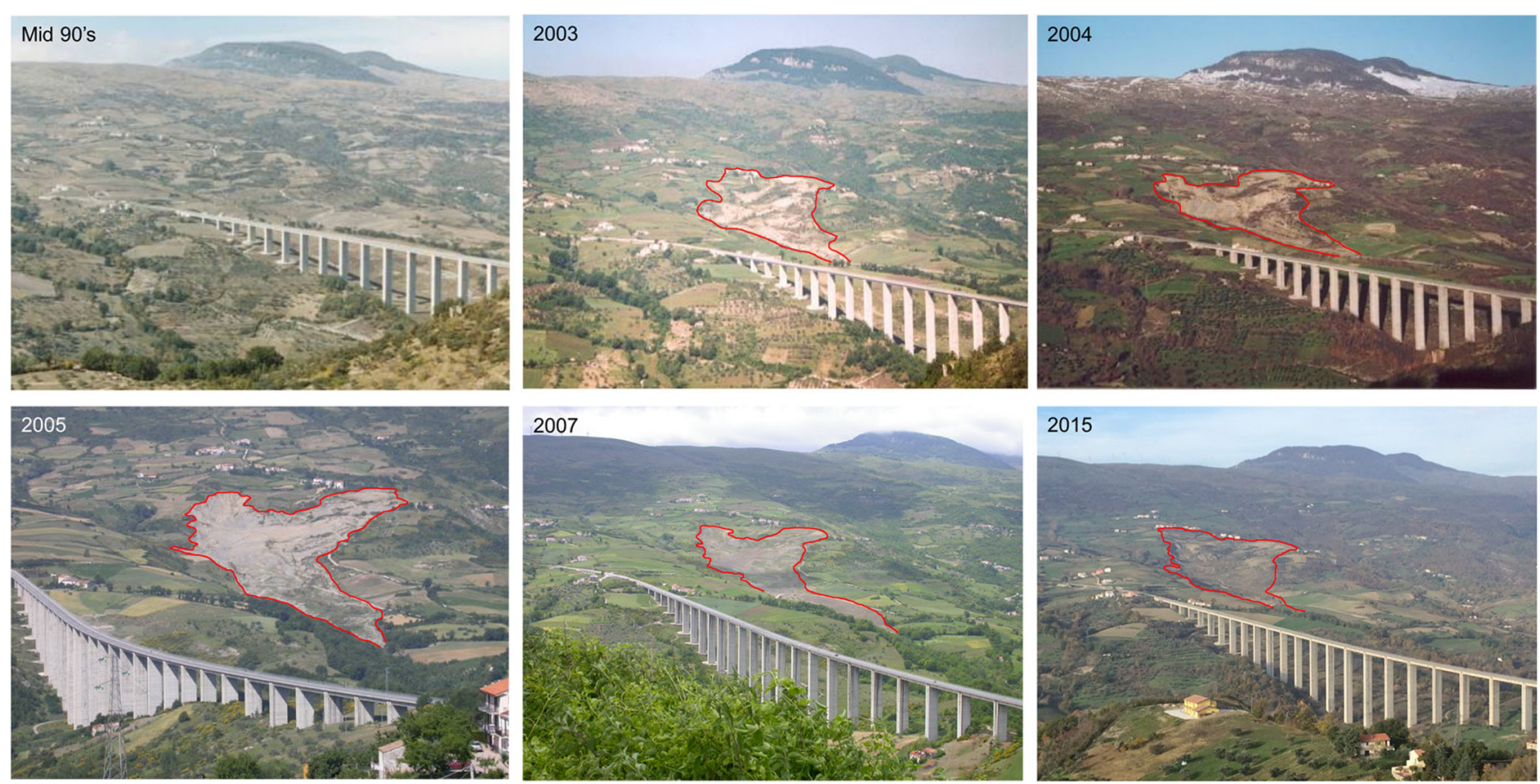

Fig. 3 Decadal evolution of the CL-PO landslide. a) Mid-1990s, b) 2003, c) 2004, d) 2005, e) 2007, f) 2015

formulation of future realistic scenarios concerning the evolution of the slope instability (e.g., Calcaterra and Parise 2001; Calcaterra et al. 2003) and the detection of potential reactivations and impacts of the phenomenon.

Landslides have been known in the municipality of Agnone since at least the beginning of the twentieth century. The oldest report describing an instability event refers to a phenomenon that occurred in March 1905 in the San Nicola Valley due to the combination of a period of intense rainfall and snowmelt (Calcaterra et al. 2008, Fig. 4a). This event damaged the bridge that carried the main access road to the historical center of Agnone (Almagià 1910).

The municipality of Agnone has been successively affected by several small and large landslide events. Archival and bibliographical landslide research, reported in the nationwide AVI Project (Guzzetti et al. 1994), revealed more than 60 landslides that occurred in the municipality of Agnone and the surrounding territory from 1970 to 1998. In February 1984, a mass movement occurred close to the study area that affected two pillars of the viaduct of a State Road (Guadagno et al. 1987), forcing the demolition of a section of it (Fig. 4b). In 1994, a mass movement affected the ColleLapponi area, causing the interruption of a dirt road.

Finally, the latest landslide inventory of the municipality of Agnone was conducted by the IFFI Project (Italian Landslides Inventory Project) by ISPRA (Istituto Superiore per la Protezione e la Ricerca Ambientale) in 2008.

\section{Reactivation of the CL-PO landslide}

After an intense rainfall event that affected southern Italy between the 23rd and the 27th of January 2003, with more than $200 \mathrm{~mm}$ of rain falling over $72 \mathrm{~h}$, the investigated area was involved in an important reactivation of a dormant historic landslide due to an unusual increase in pore pressure (Calcaterra et al. 2008). In the municipality of Agnone, a cumulative precipitation of approximately $50 \mathrm{~mm}$ was measured in the meteorological station located in CL-PO (Lat $41.80^{\circ}$ and Long $14.33^{\circ}$ ) belonging to Regional Agency for the Agricultural, Rural and Fishing Development (Agenzia Regionale per lo Sviluppo Agricolo Rurale e della Pesca ARSARP - www.arsarp.it/agromtorologia) in the same period in which a reactivation of the landslide (Calcaterra et al. 2008), with a complex style consisting of a succession of large roto-translational slides by an earth-flow (Cruden and Varnes 1996). The event involved several facilities, forcing the municipality's administration to adopt restrictive measures, i.e., the evacuation of 13 buildings located in the area involved in the landslide, in which 17 families were living. The municipal administration, owing to the severity of the situation, earmarked funds to perform several urgent interventions, such as the re-shaping of the area affected by the mass movement and the excavation of a trench in the upper part of the body of the landslide in order to intercept and drain the water table, which locally reached the ground surface.

During the years following the main reactivation, despite the adoption of the abovementioned remedial measures, the 
Fig. 4 Excerpt of the map published by Almagià (1910). The red box indicates the location of the CL-PO landslide (speckled in the figure); b) demolition of the State Road viaduct following the 1984 landslide (from Guadagno et al. 1994)
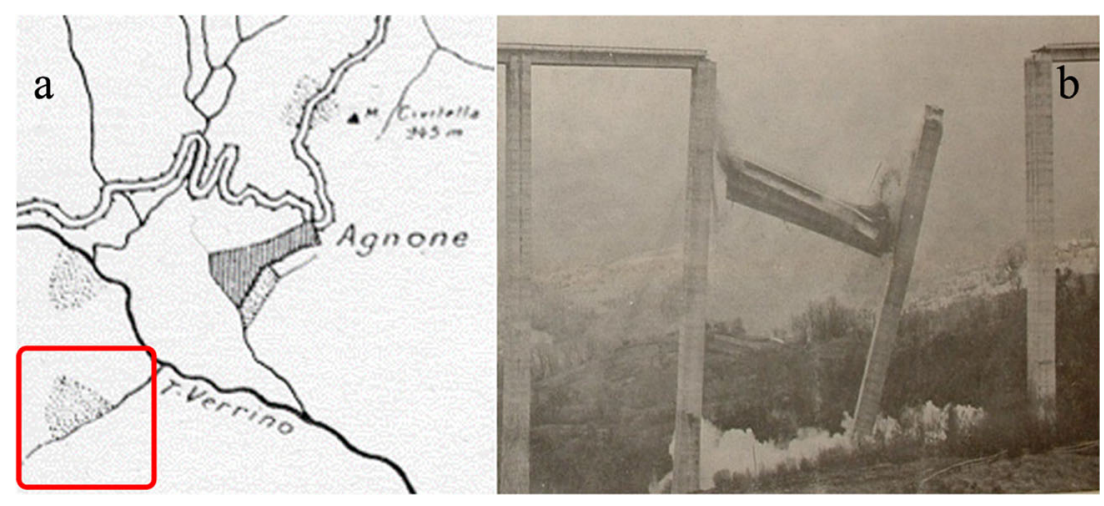

entire landslide remained active, increasing its dimensions and causing additional damage to facilities and buildings. During March 2004 and in the period between December 2004 and January 2005, the landslide was reactivated by a series of heavy rainfall events (Fig. 5), increasing the area involved and mobilizing an estimated total volume of $3.5 \times 10^{6} \mathrm{~m}^{3}$ (Calcaterra et al. 2008).

Continued advancement of the movement that resulted in progression of the landslide foot over approximately $70 \mathrm{~m}$ was recognized by June 2006, and a lower displacement rate was detected between April 2006 and April 2007. These observations led to the adoption of new mitigation measures in the middle part of the mass movement, where ground subsidence and the collection of surface runoff formed a landslide lake. Consequently, additional reshaping of the slope and the excavation of 10 trench drains $(6.5 \mathrm{~m}$ deep and approximately $150 \mathrm{~m}$ long) were performed. These actions stabilized the middle to lower parts of the mass movement. From 2004 onward, a set of topographic benchmarks were placed within the unstable areas to monitor the surficial movement of the landslide. From 2004 to 2011, the landslide advanced approximately $350 \mathrm{~m}$ at the toe and retrogressed approximately $270 \mathrm{~m}$ in the head sector, increasing the total length to $1500 \mathrm{~m}$ (Fig. 6). In 2010 and 2013, two campaigns of topographic measurements were conducted using GPS equipment to evaluate the progressive evolution of the landslide and the enlargement of the main scarp. These data confirmed the effectiveness of the stabilization works in the central and lower sectors of the landslide, but not in the upper area. Furthermore, in 2012, eight corner reflectors were installed on the mass movement to monitor the landslide (Di Martire et al. 2013) by means of Differential Interferometric Synthetic Aperture Radar (DInSAR) techniques.

In November 2015 and July 2016, additional field surveys permitted the examination of the further evolution of the slope movement and the identification of a new boundary of the landslide (red line in Fig. 6) as well as many tension cracks inside and outside the landslide boundaries. The field campaigns were mainly devoted to identify, record, and assess the severity of the landslide-induced damage on several facilities located within and close to the landslide.

\section{Methodologies for damage assessment}

Displacements that occur in landslide areas are often revealed as fractures on the ground surface or as ruptures and cracks in man-made facilities. These effects appear when ground
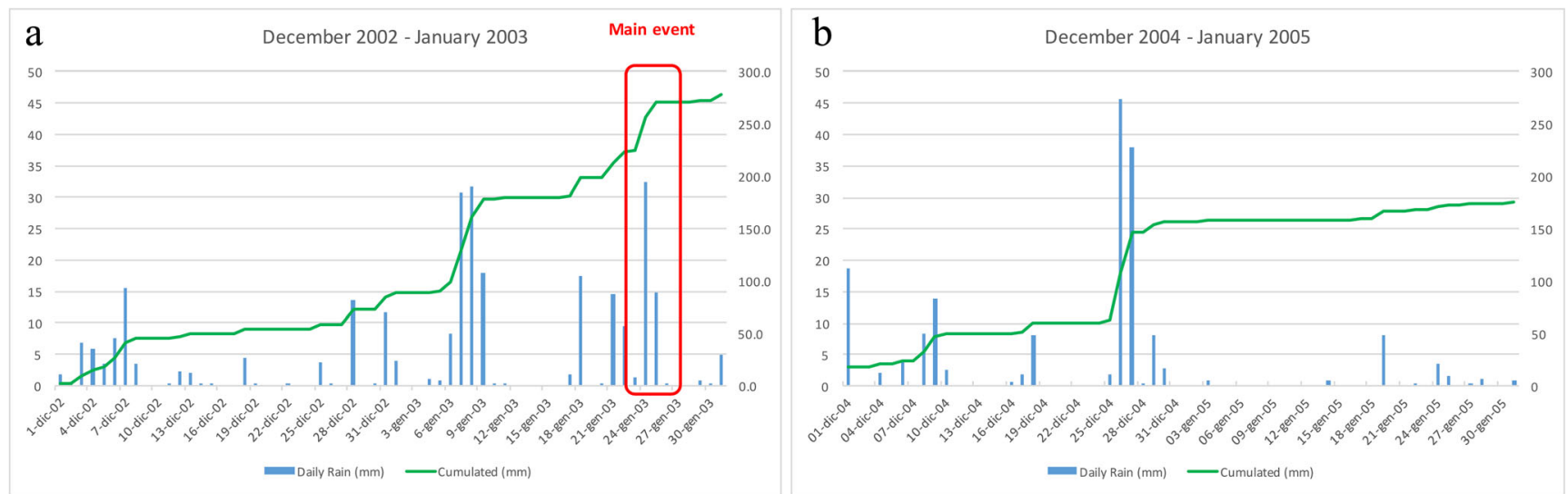

Fig. 5 Daily (blue bars) and cumulative (green line) rainfall from (a) December 2002 to January 2003 and (b) from December 2004 to January 2005 . The red box highlights the rain event, which caused the main reactivation of the landslide (www.arsarp.it/agromtorologia) 


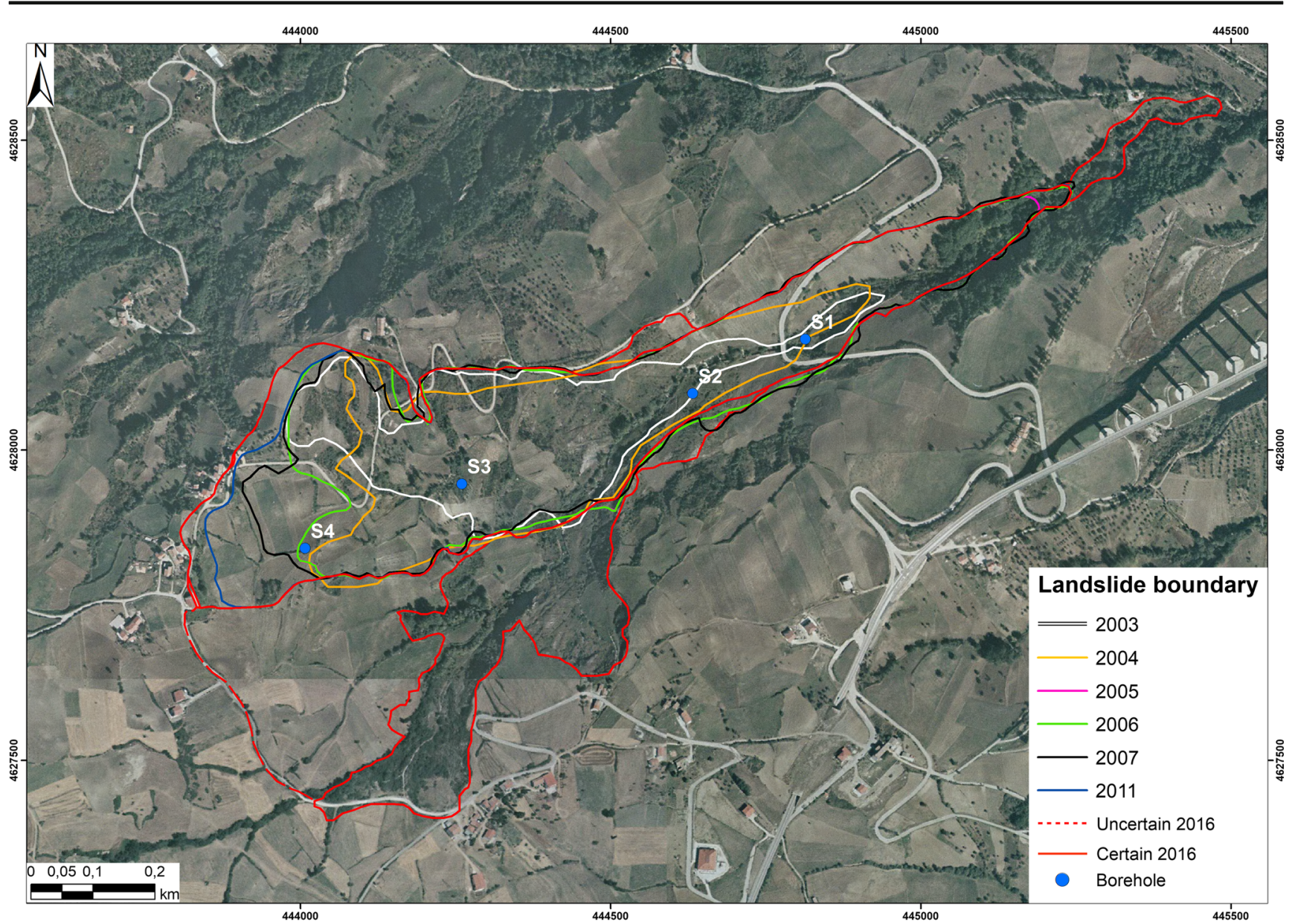

Fig. 6 Evolution of the boundaries of the CL-PO landslide from 2004 to 2011. Ground evidence recognized during the 2015 survey is drawn in red

movements that affect the buildings are greater than the tensile stresses that the structures are capable of accommodating without apparent deformation. The first elements to reveal damage are the most rigid ones, such as walls and façades, or the weakest elements, such as joints (Bru et al. 2013). Building damage is commonly assigned to three general categories: architectural, functional, and structural damage. These categories were first disseminated by Skempton and MacDonald (1956), who did not define clear boundaries between them. Architectural damage refers to the appearance of a structure (e.g., fine cracks in finishes, floor or panel walls, cracks wider than $0.5 \mathrm{~mm}$ in plaster or wider than $1 \mathrm{~mm}$ in rough concrete and masonry walls). Functional damage affects the use of the structure and produces extensive cracks, tilting of floors and walls, falling plaster, obstructed doors and windows and other non-structural damage. Structural damage reduces the stability of the structure manifesting as ruptures and distortions in support elements (e.g., pillars, columns and load-bearing walls). In practice, damage affecting facilities have to be assessed by performing field surveys, which are highly conditioned by the criteria adopted and the experience of the operators.
The scientific community has developed some specific classifications of damage for areas affected by natural catastrophic phenomena, such as earthquakes (e.g., Wood and Neumann 1931; Medvedev 1965; Grünthal 1998), subsidence (e.g., Van Rooy 1989; Howard Humphreys \& Partners, 1993; Freeman et al. 1994), and landslides (e.g., Burland 1977; Alexander 1986; Geomorphological Services LTD, 1991; Lee and Moore 1991; Chiocchio et al. 1997; Iovine and Parise 2002).

In this work, six different methods were used for classifying the observed damage to the facilities affected by the CLPO landslide. The methods include those of (a) Burland (1977), slightly modified by Boscardin and Cording (1989), (b) Alexander (1986), (c) Chiocchio et al. (1997), (d) Cooper (2008), (e) the DPC (Baggio et al. 2009), and (f) Del Soldato et al. (2017). The main characteristics and differences between the different classifications are summarized in Table 1. The application of the six different methods of classifying the landslide-induced damage allows defining the most appropriate approach for this case study. This is useful for several purposes, such as civil protection management after significant events, urban planning and managing of remedial and 
Table 1 Main characteristics of the applied methods to classify the landslide-induced damage on structures (updated from Del Soldato et al. 2017)

\begin{tabular}{lllllll}
\hline & Burland et al. & Alexander & Chiocchio et al. & Cooper & DPCBaggio et al. & Del Soldato et al. \\
\hline Year & 1977 & 1986 & 1997 & 2008 & 2009 & 2017 \\
Number of classes & 6 & 8 & 8 & 8 & 4 & 8 \\
Distinction of structure & NO & NO & YES & NO & NO & YES \\
Reference values & YES (mm) & NO & YES (cm) & YES (mm) & YES (mm) & YES (mm) \\
Partition of the structure & NO & NO & NO & NO & YES & YES \\
Applicability on ground surface & NO & NO & NO & YES & NO & YES \\
\hline
\end{tabular}

Note: ND means "not defined"

prevention measures, and architectural and engineering design.

\section{Burland 1977}

The simple approach presented by Burland (1977) was derived from the accumulated experience of the author in the field through three previous studies: i) a study of the economic consequences on the heaving of construction on swelling clay, by means of a simple classification of damage based on the ease of restoration (Jennings and Kerrich 1962); ii) a simple classification based on wide experiences in subsidence damage (National Coal Board, 1975); and iii) a categorization structure-soil interaction proposed by the Coal Board's recommendations (MacLeod and Littlejohn 1974). Burland's (1977) classification is divided into six damage classes based on the width of cracks and related to the ease of restoration. Within these classes, the widths of the cracks are approximate.

The measurement is related only to visible or esthetic damage, observed corrosion, and cracks permitting the penetration or the leakage of liquids or gases. For reinforced concrete, the adopted approach should be more severe (Nawy 1968).

\section{Alexander (1986)}

After an important landslide event occurred in Ancona, central Italy, in 1982 an alternative intensity scale of damage was developed (Alexander 1983). This method referred to the landslide-induced damage observable on buildings and permitted the comparison of the damage observed on different structures involved in the event. The proposed scale refers to landslide damage due to subsidence, rotational and translational movements, and slow thrusts rather than to the impact of the avalanching debris (Alexander 1986). This approach includes eight damage levels based on the severity and widening of cracks, the distortion of rigid elements and the degree of settlement that affects the foundations in addition to two of which correspond to the most severe categories, i.e., partial and total collapse of the structure, based on the cracks observed on walls. However, some missing features of this method have been identified during applications (Crescenzi et al.
1994; Iovine and Parise 2002). These include, for example, the type and age of construction of the buildings or the renovation works (Chiocchio et al. 1997).

\section{Chiocchio et al. (1997)}

Chiocchio et al. (1997) defined a new classification of landslide damage to buildings that overcomes some of the drawbacks that were identified in the classification of Alexander (1986). The new approach was conceived thanks to an interdisciplinary effort involving geologists, geomorphologists, and civil engineers.

This classification considers two different types of structures (i.e., masonry and reinforced concrete) and provides quantitative reference values for some parameters. These improvements were relevant to the analysis of the fractures to allow evaluation of similar cracks in different materials and to minimize the subjectivity of the survey. The damage level was divided into eight different grades and, additionally, some general recommendations for rehabilitation measurements were defined. The first three levels correspond to negligible and weak damage; buildings affected by the fourth grade of damage exhibit some serious cracks, and restoration strategies are suggested for them; the fifth grade is characterized by several failures that affect the structure and the surrounding area. The last class is assigned to buildings in which the level of damage is so severe that the extent of the damaged area has to be accurately evaluated in order to decide whether to renovate or relocate the entire construction (Chiocchio et al. 1997; Iovine and Parise 2002).

\section{Cooper (2008)}

The classification is formulated on the basis of several previous classifications for evaluating building damage caused by subsidence and landslides. The affinity between several existing schemes for recording damage caused by landslides and subsidence permitted the generation of a single scheme that describes observable damage to buildings, independent of the causes (Cooper 2008). This classification also divides the severity of the damage into seven classes, from very slight to 
total collapse, in addition to a class describing negligible damage. The definition of the categories was based on studies by the National Coal Board (Handbook 1975), Alexander (1986), Geomorphological Service Ltd. (1991), Freeman et al. (1994), the Institution of Structural Engineers (1994), and Chiocchio et al. (1997).

In this classification, ground damage caused by landslides and subsidence were included considering that most of the survey was performed by studying the external façades of buildings. In this approach, damage to roads and other facilities can also be surveyed and could even be evaluated (Cooper 2008). Cracks and fractures observed on facilities and the ground surface are related to more severe damage classes (above the third grade).

The damage grades are described by a scheme without details on cracks in foundations or other subsurface features, as Cooper (2008) considered that the recording of damage using more practical parameters has proven to be popular, simple, and easily performed in field surveys.

\section{The Italian Department of the Civil Protection approach (Baggio et al. 2009)}

This method was conceived for surveying damage that affects civil construction after seismic events in order to assess the fitness for human habitation of the buildings. The applicability to landslide phenomena is derived from the causes of the damage due to the effects of shear stresses in both cases. This method was applied in several field situations involving seismic events in Italy (e.g., 1980 Irpinia earthquake in Campania, the Abruzzo region in 1984, and the Basilicata region in 1990) and it was tested in subsequent earthquakes (e.g., the Umbria-Marche regions in 1997, and Pollino and the Basilicata-Calabria regions in 1998) with the view to enable making judgements on the ability of structures to host their inhabitants safely, so it does not address protection of the structures.

This approach was devised to perform initial classifications of damage magnitudes by means of quick surveys. It was conceived to assess the reliability of structures. Therefore, the recording scheme for the damage is more complete than the one presented previously. It is composed of several tables suitable for emergency post-seismic event surveys. Overall, this recording scheme is composed of nine sections: a) three tables devoted to the identification and description of the examined buildings; b) two sections referred to a quick assessments of structural and non-structural damage; c) a section dedicated to evaluating the possible involvement of surrounding structures in case of the collapse of edifices; d) a section that addresses the geomorphological condition of the terrain surrounding of the buildings; e) a section to assess the building's conformity with standards; and f) a final section to include notable and useful information. The main contribution of this approach with respect to the previous approach is the introduction of the extent of damage.

For the aim of this work, only the two sections related to recording structural and non-structural damage were considered, in addition to the introduction of the evaluation of the extension of the cracks as affecting less than $1 / 3$, a portion between $1 / 3$ and $2 / 3$, or more than $2 / 3$ of the building for each class of damage. According to this approach, the investigation of structures has to be ideally divided in three parts considering intervals of $33 \%$ or $67 \%$. Additionally, the magnitude of the damage that affects each part of the structure can be assessed as null (D0), weak (D1), medium-severe (D2-D3), and very severe (D4-D5). The sum of the extent of the damage cannot exceed 1 , representing the entire building (e.g., 2/3 of D4-D5 + 1/3 of D2/D3).

The DPC classification was originally developed to evaluate the fitness for human habitation of buildings after a seismic event. Therefore, for comparing the results obtained by this approach to the others mentioned above, a further consideration was necessary to have the same number of classes. All possible combinations, considering the extent of the damage for each class and the four classes of cracks (D0, D1, D2-D3, D4-D5), were considered. Then, a conversion matrix was used to evaluate the seriousness of the damage affecting a single unit according to the possible combinations of damage. For each level of damage, a value was assigned and then grouped into eight classes varying from 0 (negligible damage) to 7 (total collapse) in order to compare the resulting map with the other described classifications.

\section{Del Soldato et al. (2017)}

This classification was developed through the application and analysis of results of previous approaches to provide a rapid evaluation of cracks and fractures during field surveys and a subsequent assessment of the buildings damage caused by landslides. To create this new classification method, several landslide-induced categorizations of damage to buildings were considered (Burland 1977; Alexander 1986; Chiocchio et al. 1997; Cooper 2008) jointly with the approach for the assessment of seismic event effects developed by the DPC (Baggio et al. 2009) to insert the importance of the extension of the cracks and fractures in the damage evaluation. Furthermore, similar to the Cooper (2008) approach, external recognition plays a key role, and the ground fractures are also considered. Ground cracks are not considered related to the constructions, but singularly, in order to implement the knowledge regarding severity and extension of the landslide effects. The classification is divided into six ranks from no damage to very severe. In this categorization, the collapse is not considered because in the first phase the focus is the network of cracks and fractures that affect the structures. Subsequently, the extent of the damage has to be considered and, by means of a matrix, the entire building could be classified into eight 
classes from "no damage", meaning safe construction, to "unusable", indicating an uninhabitable building.

\section{Description and classification of damage}

The January 2003 landslide reactivation was the most recent event that caused serious damage to facilities and buildings in Agnone. Damages were chiefly related to the loss of support to structures due to the downward and outward movements of the foundation zones (Hunt 2005). This effect was important for forcing the administration of the local municipality to take some restrictive measures, such as a precautionary evacuation of several houses located close to the area that were affected by the slope movement. In November 2015 and July 2016, forensic analyses were conducted for 30 buildings, two walls, and three concrete surfaces near the landslide; one electric tower close to its left flank; and several tension and shear cracks on ground surface and pavements. For this purpose, external damages were surveyed using a regular scheme (see supplementary material by Del Soldato et al. 2017) in order to collect as much information as possible: i) date and site of the survey, hamlet, municipality, and province; ii) identification number of the structure under investigation; iii) coordinates of the façades; iv) type of construction, e.g., buildings, gymnasium; v) load-bearing materials, e.g., masonry or concrete; vi) date of construction and number of floors of the edifice; vii) position with respect to the landslide; viii) draft and classification of the ruptures of on ground and pavement; ix) drawing and categorization of cracks on buildings; $\mathrm{x}$ ) extension of the damage in all structures or only in its portion; and xi) georeferenced photographs. The procedure for collecting such information is considered important inasmuch that the same opening, or two similar cracks, in two structures built with different materials could have different meanings (Chiocchio et al. 1997; Iovine and Parise 2002).

Different levels of damage that affect the buildings are grouped into several types:

- hairline cracks (Fig. 7a);

- open fractures on external walls (Fig. 7b and c);

- ruptures between walls and external pavements (Fig. 7d and e); and

- in rare cases, roof collapses (Fig. 7f).

In concrete sidewalks and walls, the following elements were investigated:

- hairline cracks (Fig. 8a and the red arrow in 8c) and

- open cracks (Fig. 8b-d).

Cracks recognized on the ground (Fig. 9b) or on pavements (Fig. 9a) were plotted on a topographic map and photographed as well as spatially identified with a GPS tracker.
These types of fractures on roads and ground surfaces (Fig. 10) are investigated and classified only by the most recent approaches proposed by Cooper (2008) and Del Soldato et al. (2017). The identification and survey of these fractures, the assessment of their severity, and the investigation of their probable correlation to the activity of the landslide, can be important parameters to support the identification of extension of the landslide-prone area.

An example can be made taking into account a sidewalk made of reinforced concrete (Fig. 10) that is located in the present crown of the landslide that currently shows an important open crack pattern with detachment of a portion (Fig. 10b). In recent years, the crown of the landslide has retrogressed, widening its boundaries and increasing its dimensions, as reflected in the opening of new tension cracks and the collapse of a part of the sidewalk bordering a building that does not show severe damage to the external façades.

The in situ analyses provided qualitative and quantitative information about the fractures used for damage assessment of the studied elements, according to the six classifications described earlier (Table 2 and Fig. 11), one for each methodology applied to record the damage to the facilities located within the landslide-prone areas. It is worth noting that, although these methodologies were originally proposed for the identification of damage to buildings, in this work they were also applied to categorize other man-made elements (i.e., an electricity mast, two walls, and three concrete areas) that were strongly affected by ruptures. The results show that most of the damage is located in areas where the landslide remains active. Several structures, buildings and infrastructures, in and close to the mass movement, therefore, within the landslide prone-area, were investigated (Fig. 11a).

\section{Results}

In this section, the results derived from the damage assessment of the building and the infrastructures placed in CL-PO landslide by means of the different approaches described earlier are presented.

Following the classification of Burland (1977) (Fig. 11b), a large number of buildings (approximately 50\%) present Slight and Very severe damage, as several abandoned structures are strongly affected by damage and have partially collapsed. Only two buildings have been assigned to the Negligible class, and four fall into the Very slight class. Negligible damage were observed in more recent structures, in a small house that was probably renovated in recent times and in buildings that were built further from the landslide than the others. The Very slight class includes a building located on the present-day crown of the landslide. This rank is due to the low level of damage present in its façades, although important damage could affect its foundation. 

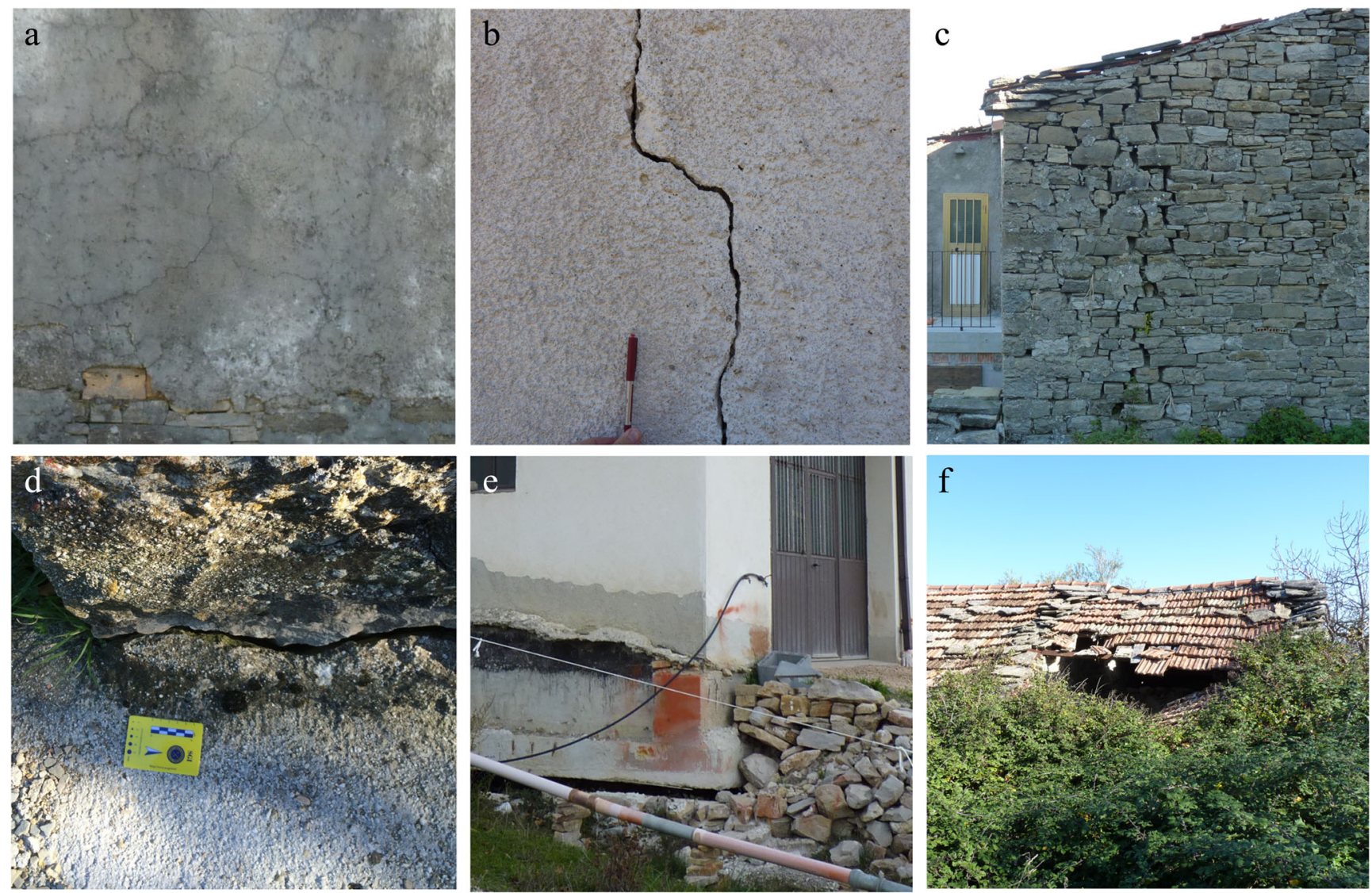

Fig. 7 Damage identified on buildings. a) Hairline crack in the plaster of a masonry wall; b) open crack, approximately $1.0-1.2 \mathrm{~cm}$ wide, in a wall of a reinforced concrete building; c) open crack, approximately $4 \mathrm{~cm}$

and the pavement in a masonry building; e) open crack, more than $10 \mathrm{~cm}$ wide, between a wall and the ground surface of a reinforced concrete building; f) collapsed roof in a masonry building wide, in a wall of a masonry building; d) open crack between a wall

Alexander's (1986) (Fig. 11c) classification measures crack apertures in centimeters instead of millimeters. This implies that the classification is less sensitive to damage, and most of the facilities are grouped into the Light and Moderate classes. Additionally, in this classification, "evacuation and rapid attention to ensure" is recommended for those facilities that exhibit Moderate damage. Concerning the buildings located on the crown of the landslide, this methodology classifies the damage as Negligible, despite the existing high risk. Another noteworthy point is that this methodology considers two categories for buildings that are strongly affected by damage: Partial collapse and Total Collapse. The nine buildings assigned to the Very severe class using the Burland (1977) approach are divided into three classes according to Alexander's (1986) classification: three of the buildings fall into the Very serious class, five fall into the Partial collapse rack, and one falls into the Total collapse category.
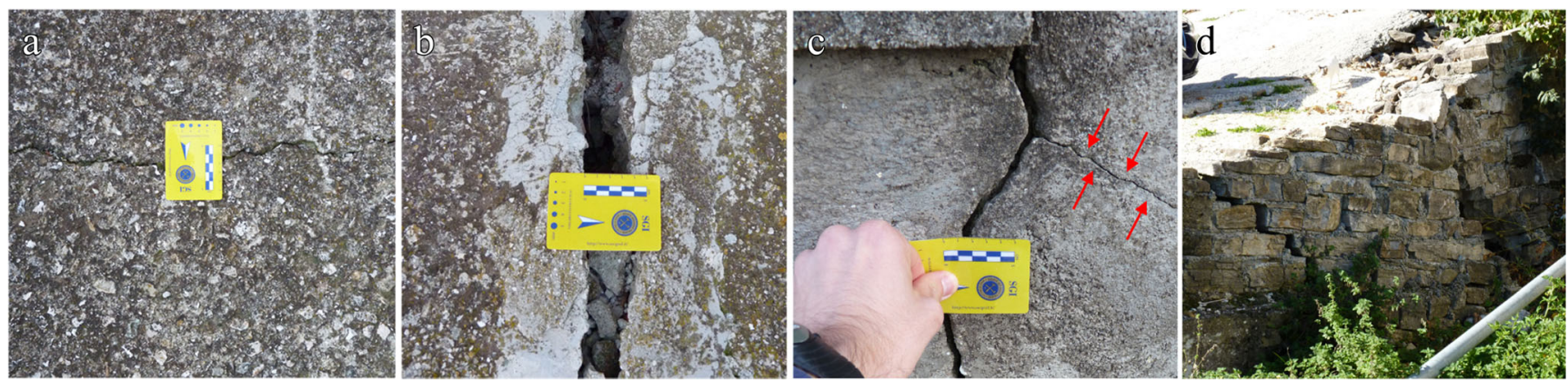

Fig. 8 Damage recognized on concrete slabs and walls. a) Hairline crack in pavement; b) open rupture in a slab; c) hairline (red arrows) and open fractures in a concrete wall; d) damage to a masonry wall 
Fig. 9 Cracks located close to the landslide on (a) the pavement of a road and (b) the ground surface. In photograph (b), a vertical slip is recognized
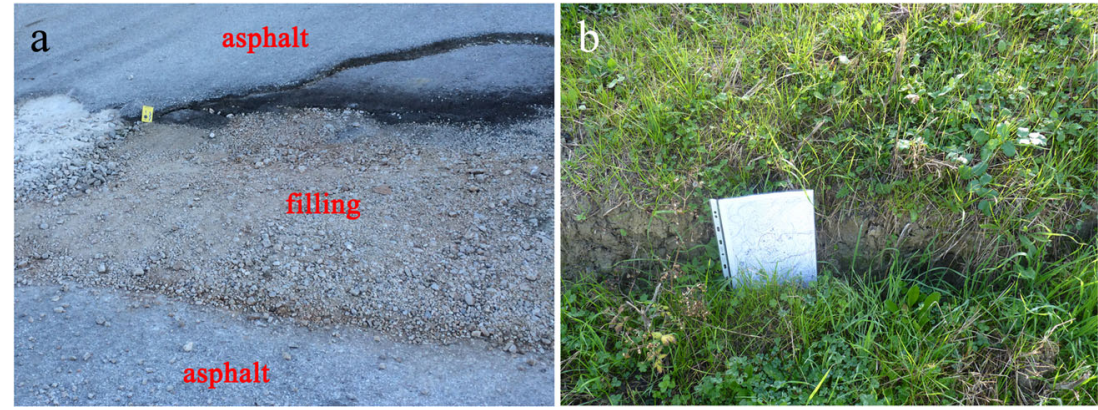

The Chiocchio et al. (1997) (Fig. 11d) approach also measures cracks in walls using centimeters. However, this approach includes the construction distinction between masonry and reinforced concrete, in contrast to the previously mentioned methodologies. In this way, structures affected to a significant degree by rigid settlement, which were previously assigned to the low damage classes, are grouped with those affected by several cracks. A concentration of buildings is assigned to the Light and Moderate damage classes, and the authors suggest evacuation even for the Moderate category. Moreover, it is important to note that using this categorization, the building (B01) located on the probable present-day crown of the landslide has few, narrow visible cracks in its external façades, perhaps justifying the low damage classes assigned by the classification, despite an important rupture that affects the front concrete sidewalk. Six buildings, probably abandoned several years before the main event, are assigned to the highest categories of damage (i.e., Partial collapse and Total collapse), as in the Alexander (1986) approach.

In his approach, Cooper (2008) (Fig. 11e) introduces the description and categorization of landslide ground damage in addition to the classification of the damage recognizable on facilities and buildings. This classification uses millimeters to measure the opening of the cracks that appear on the elements of the investigated structures. In our case study, the classification assigns an important number of buildings to Class 3, compatible with the Moderate category of the other approaches. Comparing the proposed classification with the other areas, more facilities are sorted into the higher levels of damage. This is probably due to the method's higher sensitivity in assessing damage that is caused by the use of the millimeter as the unit of measurement, and it is a more appropriate methodology for classifying ruptures that affect some facilities, such as pillars, walls, and concrete sidewalks.

The DPC approach (Baggio et al. 2009) divides the level of damage into four classes, although the classification includes eight damage classes: two low levels (None and Negligible), four categories representing significant damage (Severe, Very severe, Partial, and Total collapse), and two intermediate grades (Slight and Moderate) (Fig. 11f). This approach provides a more evenly distributed classification of damage (thus most of the buildings are not ranked into only one or two classes) than the previous described and applied approaches. Despite the small number of facilities located in the study area, an increasing number of structures are ranked into the categories reflecting high levels of damage (Severe and Very severe). This methodology gives more attention to damaged buildings since it was conceived to evaluate the fitness for human habitation of structures after a damaging seismic event.

The Del Soldato et al. (2017) categorization provides a homogeneous distribution of the structures located in the landslide-prone area due to its simple but detailed approach that includes two phases. These two steps of damage evaluation and subsequent structure assessment in sensu stricto allow a better discrimination of the severity of cracks and fractures. Similar to the Cooper (2008) approach, the investigation takes into account the external portions of the structures eliciting an increment in the low ranks of the buildings affected by weak fractures in external facades but relevant fractures and displacement in the foundations. Several
Fig. 10 Evolution between 2003 (left) and 2015 (right) of a reinforced concrete perimeter sidewalk of a building located on the crown of the landslide
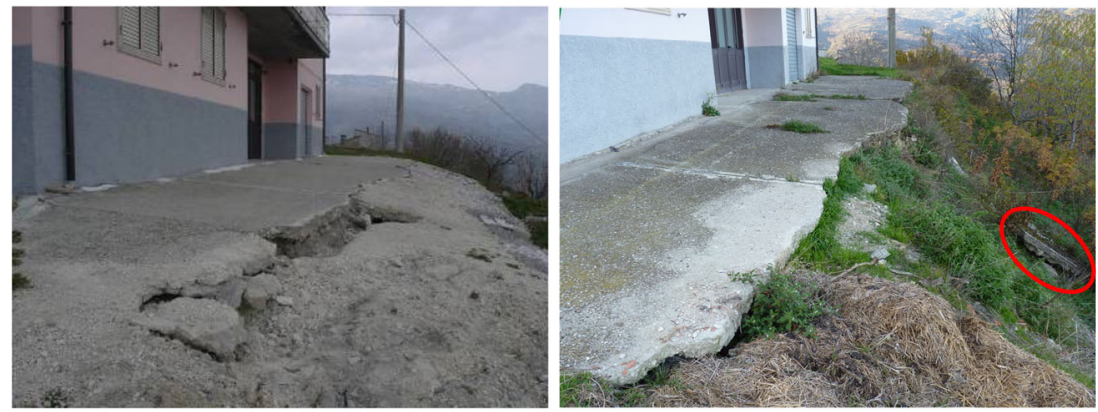


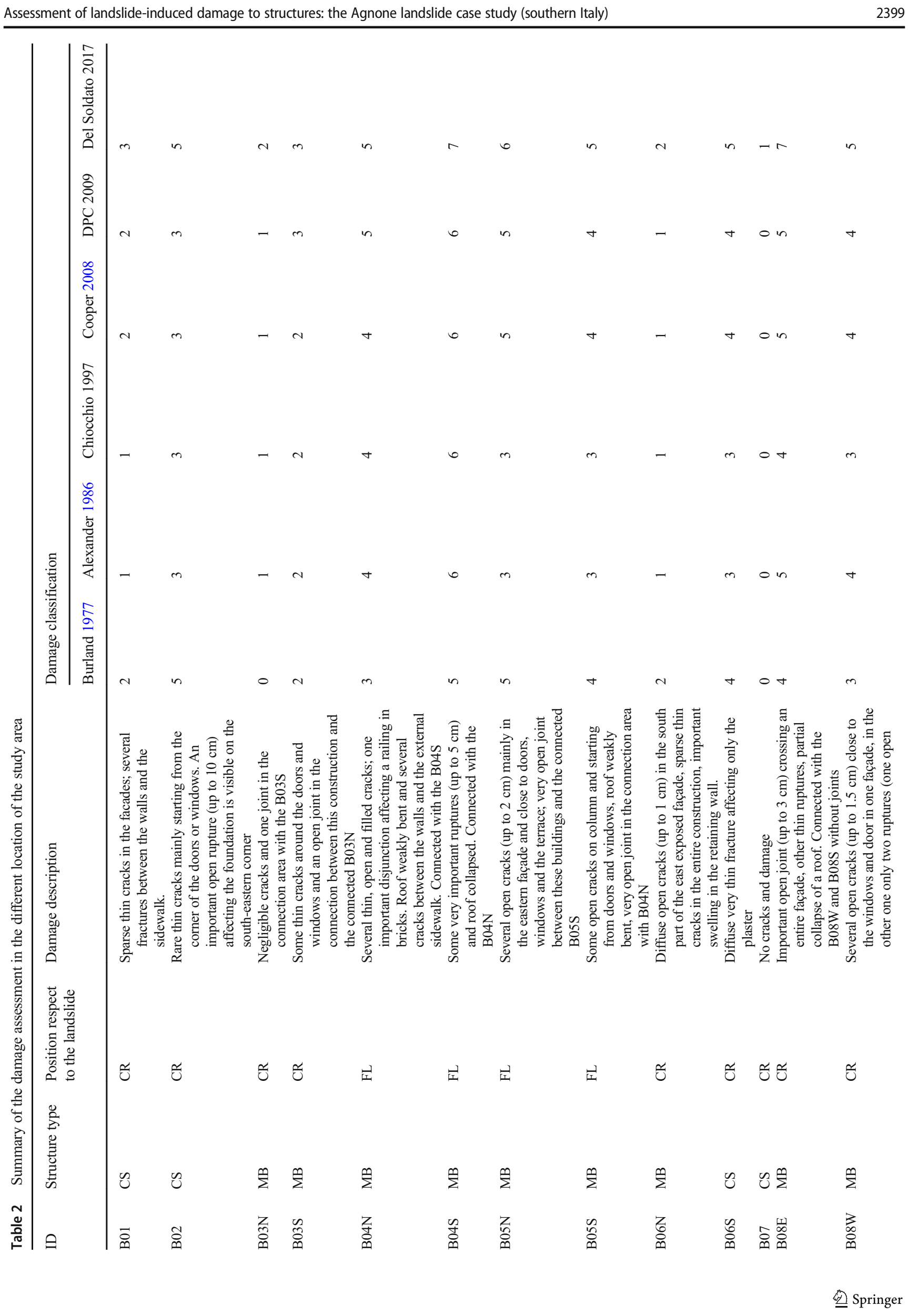




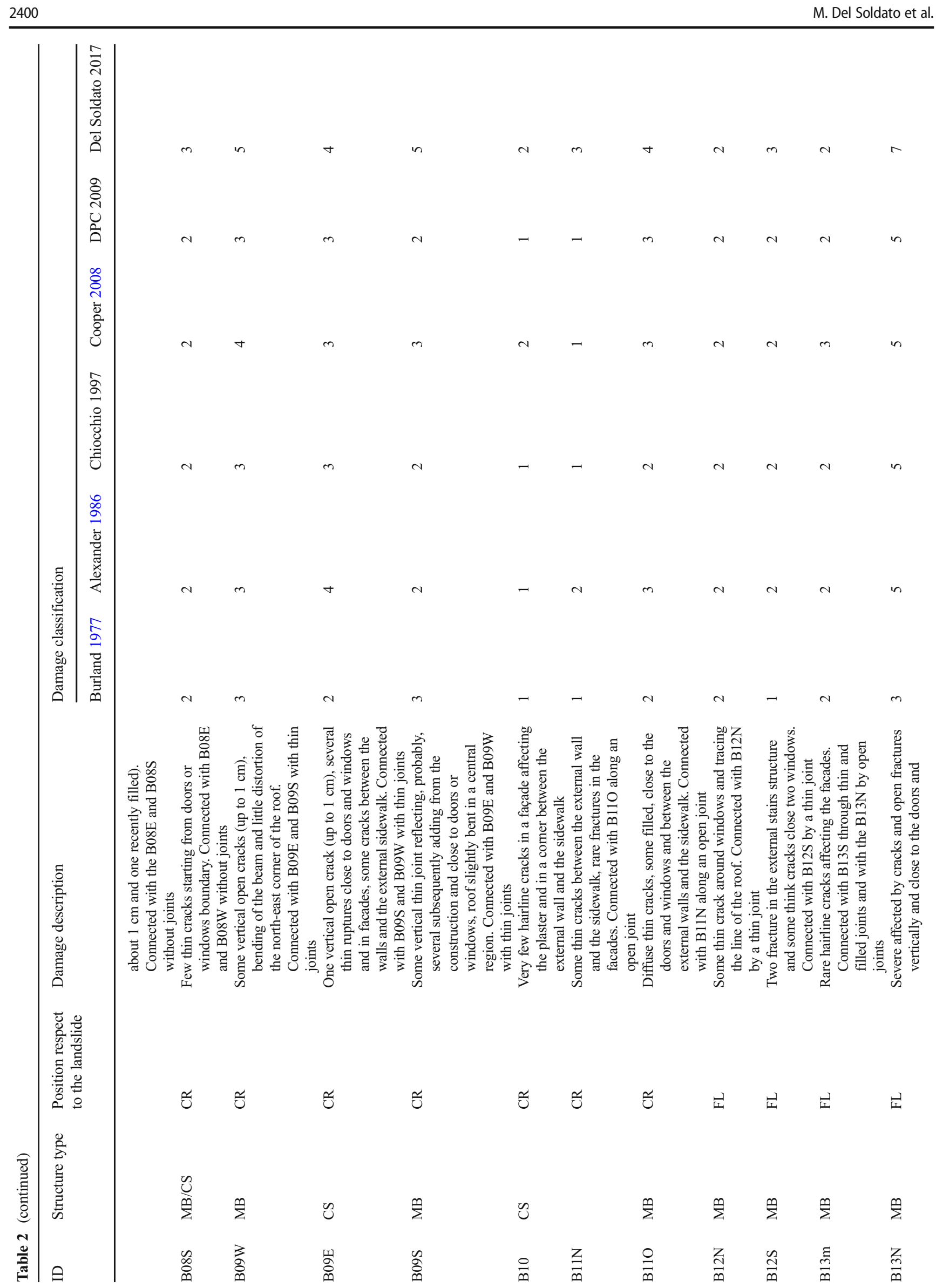

里 Springer 


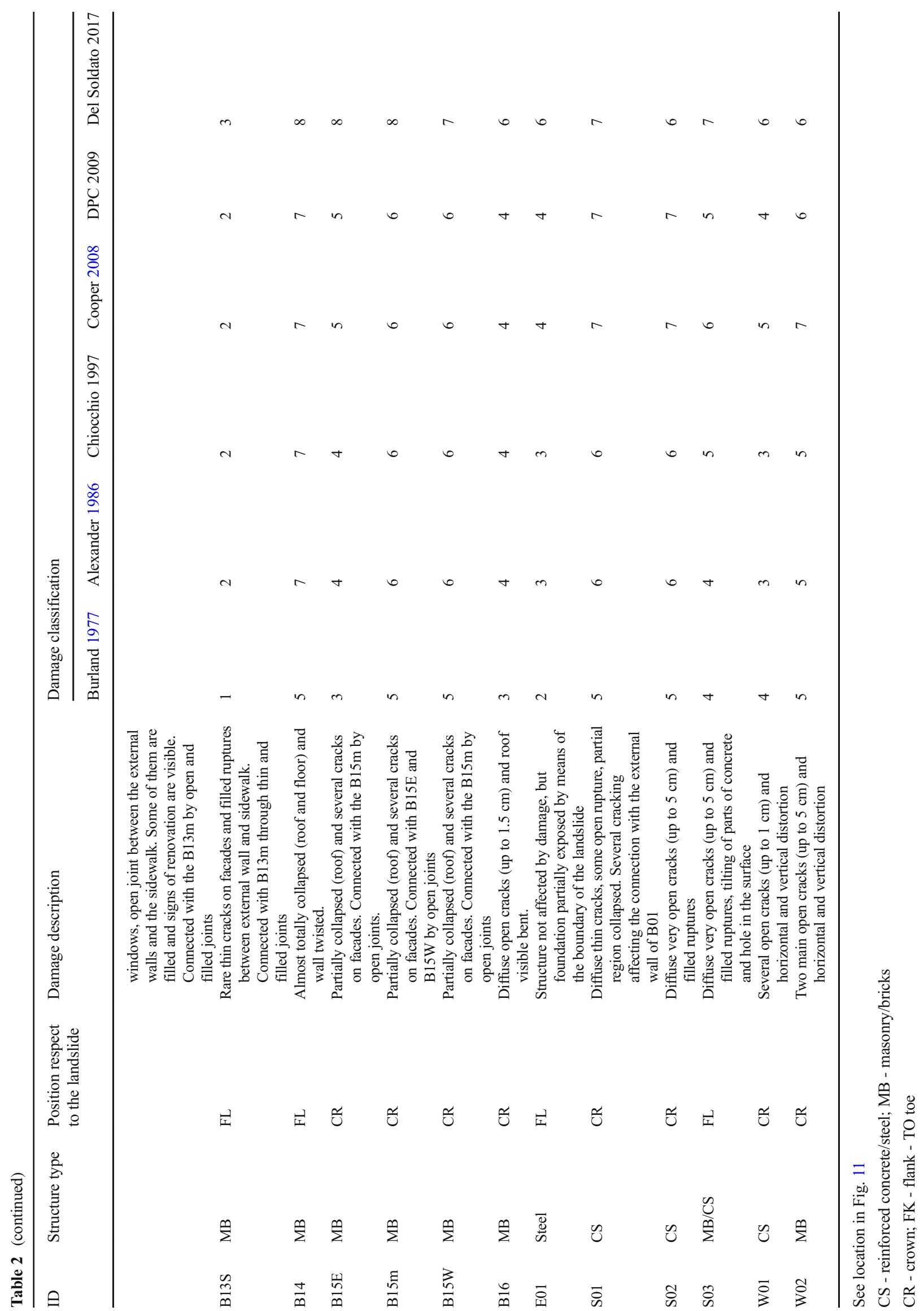



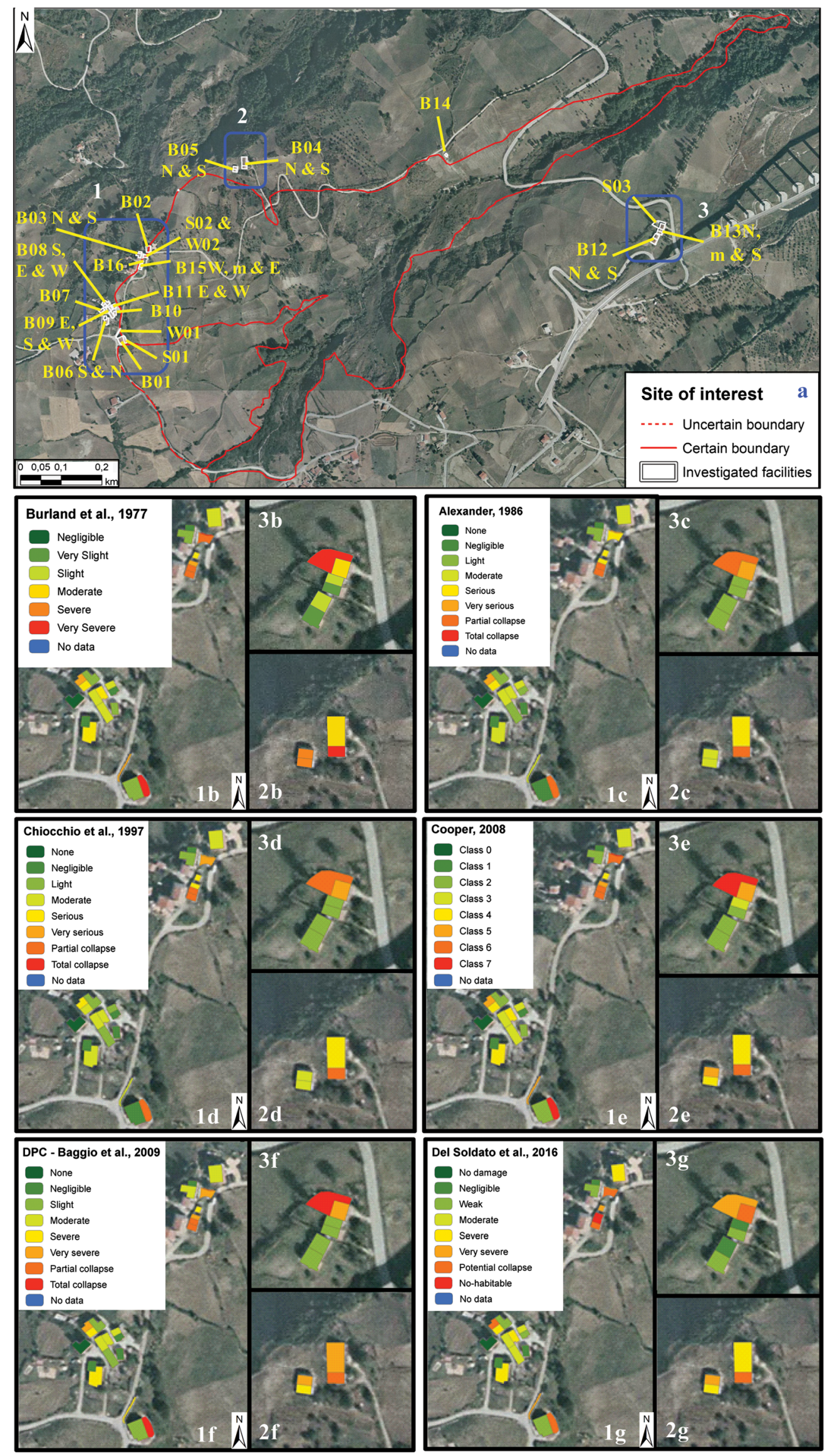
4 Fig. 11 a) Localization of the investigated buildings and facilities with their damage classifications according to b) Burland et al. (1977), c) Alexander (1986), d) Chiocchio et al. (1997), e) Cooper (2008), f) DPC (Baggio et al. 2009), g) Del Soldato et al. (2017)

constructions are categorized in the low ranks of damage (Negligible and Weak), and a relevant number is characterized by important damage (Moderate and Severe). In the left flank of the landslide (i.e., area 2), the constructions are categorized with a high level of damage (Severe and Very severe) due to the important displacement caused by a double component of movement. The first displacement component affects the right side of the study area that is under the influence of the CL-PO landslide. The second component is due to an enlargement of the mass movement that affects the neighboring basin. The three sidewalks and the two investigated walls are all categorized into a high level of damage (Severe and Very severe) due to the open cracks and fractures that affect them and, in one case, the detachment of a portion of the sidewalk due to the regression of the landslide border. Only one edifice is featured by No damage due to its recent construction or renovation. Three structures are classified as Total collapse: two of them, both abandoned, are close to the crown, whereas the third is close to the left flank of the landslide.

In addition to the structures, walls and sidewalks, an electricity mast located on the left boundary was investigated in order to assess its safety due to its important function for the surrounding edifices. This element is a steel rigid structure, founded on a concrete sidewalk. The approaches proposed by Burland (1977), Alexander (1986), and Chiocchio et al. (1997) assign this facility to the medium level of damage, despite the displacement observed on the south-eastern side of its foundation. However, the DPC (Baggio et al. 2009), the Cooper (2008), and the Del Soldato et al. (2017) methods classify the damage to this facility as very severe. The stability conditions of the pillar base are characteristic of problems that affect structures located close to the landslide crown or flanks (e.g., the two buildings located at the top of the landslideprone area). The lateral boundary of the landslide is located under the electricity mast, as seen from the ground displacement on one side of the mast, whereas no signs of movement are present on the other side.

\section{Discussion}

Several landslides affect the municipality of Agnone (Molise region, southern Italy) according to the historical investigations and reconstructions described in the literature. In 2003, the CL-PO area was affected by an important reactivation of an old intermittent mass movement, attracting public attention because of the severe damage caused to surrounding buildings and facilities. The local authorities were forced to evacuate some families from their dwellings due to the serious damage that was caused to some structures. Despite the realization of relevant stabilization works in the landslide body, the following years exhibited an enlargement of the dimensions of the landslide. The advancement of the toe and retrogression of the main scarp, with consequent involvement of the lateral flank to accommodate the movement, represents a threat of damage to facilities and buildings located in the surrounding area.

This paper focused on the comparison of six different methods of landslide-induced damage classification for facilities and buildings located in a landslide-prone area, a fundamental parameter to prioritize further investigations. The classification step can help local administrators decide where more detailed structural analyses should be performed or where further actions must be considered. Furthermore, in emergency cases, this preliminary structure classification may be sufficient to support the order of some restrictive measures, the fulfillment of practice repairs or reinforcement of the main damaged structures. For this purpose, six assessments of landslide-induced damage approaches (Table 3) were applied and compared. The six classification methods, which seemed to be very different from each other, were found to have strong similarities. In addition to a general comparison, two buildings, one located upslope with respect to the crown of the CLPO landslide and the second on its left flank, were chosen to analyze and discuss in detail the application of the features of the different methodologies for assessing landslide-induced damage.

The first building (Fig. 12a) is located on the present-day crown of the landslide, as indicated by a significant ground fissure that cuts across under the entire structure. The displacement affects the building's foundation and is easily recognizable in the building's southeastern corner (red circle in Fig. 12a) by an evident opening with respect to the ground up to $10 \mathrm{~cm} /$ year. The six applied approaches evaluate the damaged structures differently, depending on the element on which they are focused. However, all of them assessed the damage level as Moderate, except the classification developed by Del Soldato et al. (2017). The method proposed by Burland (1977) does not consider ruptures involving building foundations but only the cracks on the façades. In this case, aside from the considerable ground fissures that threaten the foundations, no heavy relevant damage to the façades were surveyed. Alexander's (1986) classification mainly considers the degree of settlement that affects structures instead of the wide cracks that may exist in the walls or structural elements, but given the complexity, the structure was assessed with the same entity of damage. The method suggested by Chiocchio et al. (1997) considers both the degree of settlement that affects structures and recognizable fractures on the façades. The low level of damage to the external walls compensates for the substantial and continuing displacement that affects the foundations of the building, reducing the severity of the 
Table 3 Equivalence of the damage categories considered by the different classifications

\begin{tabular}{|c|c|c|c|c|c|c|c|c|c|c|c|}
\hline \multicolumn{2}{|c|}{ Burland, 1977} & \multicolumn{2}{|c|}{ Alexander 1986} & \multicolumn{2}{|c|}{ Chiocchio et al., 1997} & \multicolumn{2}{|c|}{ Cooper 2008} & \multicolumn{2}{|c|}{ DPC Baggio et al., 2009} & \multicolumn{2}{|c|}{ Del Soldato et al., 2017} \\
\hline 0 & Negligible & 0 & None & 0 & 0 & 0 & None & 0 & None & G0 & No damage \\
\hline 1 & Very slight & 1 & Negligible & 1 & Negligible & 1 & Negligible & 1 & Negligible & G1 & Negligible \\
\hline 2 & Slight & 2 & Light & 2 & Light & 2 & Light & 2 & Light & G2 & Weak \\
\hline 3 & Moderate & 3 & Moderate & 3 & Moderate & 3 & Moderate & 3 & Moderate & G3 & Moderate \\
\hline 4 & Severe & 4 & Serious & 4 & Serious & 4 & Serious & 4 & Severe & G4 & Severe \\
\hline \multirow[t]{3}{*}{5} & Very severe & 5 & Very serious & 5 & Very serious & 5 & Very serious & 5 & Very severe & G5 & Very severe \\
\hline & & 6 & Partial collapse & 6 & Partial collapse & 6 & Partial collapse & 6 & Partial collapse & & \\
\hline & & 7 & Total collapse & 7 & Total collapse & 7 & Total collapse & 7 & Total collapse & & \\
\hline
\end{tabular}

classification to the Moderate class instead of a worse class, as would be expected. Cooper's (2008) approach, in contrast to the previous two classifications, only considers the width of the cracks that affect the external façades of structures. However, although this approach does not consider the settlement that affects the internal or hidden portions of the structures, it categorizes this building as Class 3 (comparable to a Moderate) on the opening and the frequency of the cracks. The DPC method (Baggio et al. 2009), which also considers the extension of damage that affects the structures, allows a more precise assessment of the damage. The structure shows cracks assessed as very important (D4-D5) for one portion and, for the remaining $2 / 3$, occasional cracks (D1). To evaluate the edifices sensu strictu, the conversion matrix combines the different contributions from the severity and the extent of the damage in order to produce a result comparable to that of the previous approach. The new approach (Del Soldato et al. 2017) that combines all previous methods allows the analysis to be performed in more detail, including the extension of the damage and the frequency and the opening of the cracks. The evaluation of the damage allows for an assessment of the entire level of damage for the entire building. This approach categorized the structure as Severe due to the typology, entity, and extent of the damage.

In summary, although the six methods focus on different features caused by the movement that influences the structure, the damage was classified as Moderate, except for the Del Soldato et al. (2017) approach that considers it as Severe, reflecting some consistency in terms of the damage assessment.

The second building is located on the left flank of the landslide and is formerly connected to another adjacent structure but is now separated by a gaping construction joint (blue arrows Fig. 12b). The building is currently abandoned, the damage to the structure includes relevant (e.g., see the red arrows in Fig. 12b) and open cracks and distortions of walls and elements as well as losses of material. The application of the six approaches shows three different levels of damage classification for this structure. The differences can be explained considering the parameters considered by the various authors. According to Alexander (1986) and Chiocchio et al. (1997), the grade of damage is evaluated as Moderate. Chiocchio et al. (1997) consider centimeters as the unit to describe the opening of the cracks and include severe
Fig. 12 Damage assessment for two buildings located in the study area by means of different approaches: a) three-level concrete structure located close to the landslide crown; b) two-level masonry building positioned on the left flank of the landslide. Both edifices were classified according to the (1) Burland et al. (1977), (2) Alexander (1986), (3) Chiocchio et al. (1997), (4) Cooper (2008), (5) Baggio et al. (2009), and (6) Del Soldato et al. (2017) approaches. Damage are highlighted by red arrows, and open joints between the nearby structures are shown in blue

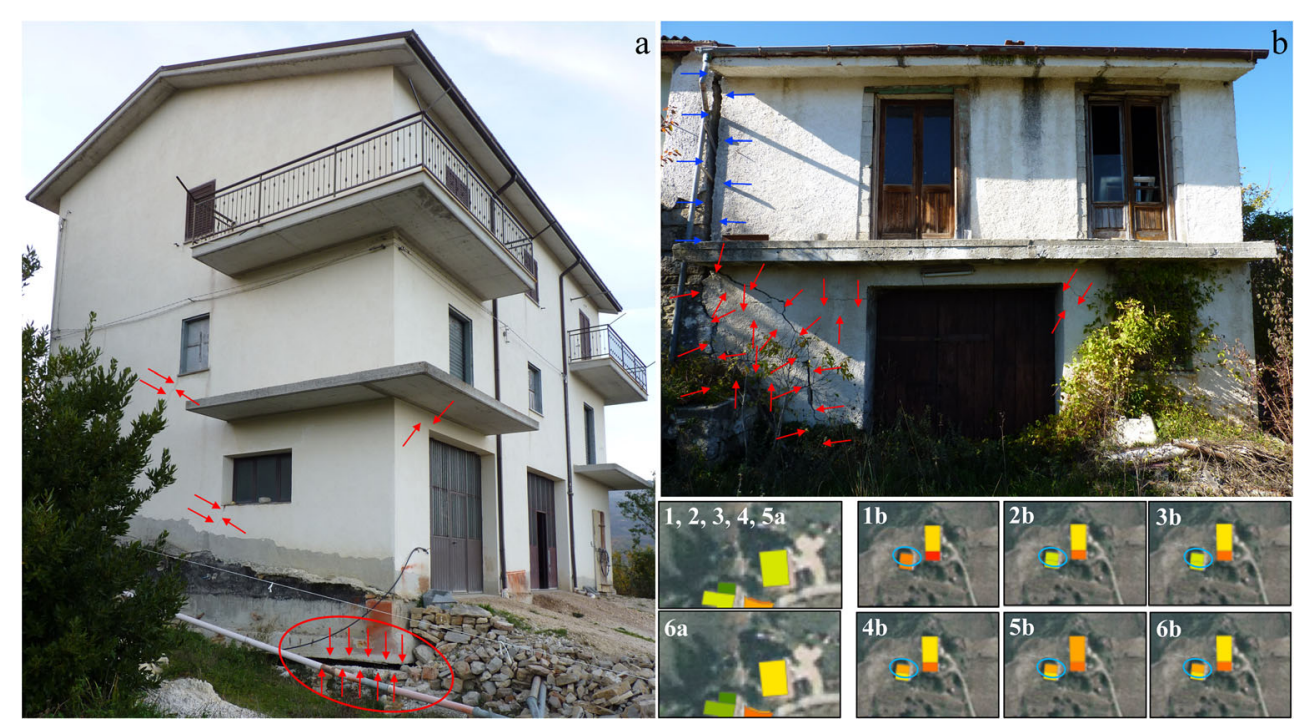


damage in the intermediate class. Similarly, Alexander's classification (1986) considers cracks that affect structural elements and distortion angles to belong to the Moderate class. The approaches described by Burland (1977) and Cooper et al. (2008) categorize the recorded damage to structures in terms of the width and number of cracks more severely than the two previously mentioned schemes, and the investigated building falls into the Severe rank. The classifications proposed by the DPC (Baggio et al. 2009) and Del Soldato et al. (2017) are the only two that classified the building as Very severe. The severity and conservative results from these two approaches could be justified by their original aim to provide quick assessments of fitness for human habitation. In addition, they are unique in that they consider the extension of the damage with respect to the entire structure combined with severity. The entity of the damage is confirmed by the conservation status of the structure, which was abandoned for several years.

For some structures, it should be possible to make a comparison between previous and future surveys (e.g., see Fig. 10) in order to detect the evolution of the damage and the structural conditions through time. Monitoring of the widening of cracks and damage to the facilities is also useful for ensuring the safety of residents as well as for understanding the temporal evolution of the landslide and reducing the possible occurrence of additional damage.

The Cooper (2008) and Del Soldato et al. (2017) approaches also take facilities, such as walls and sidewalk, in addition to the edifices, into consideration in the classification approach. In this work, structures and infrastructure were considered using all methods, and it is very interesting to note that elements different from the edifices were categorized as the highest damage levels (Very severe or Partial collapse). The results of investigating further elements with respect to the edifices, such as sidewalks, ground fractures and walls, are important for better delineating the extension of territory involved in instabilities, mainly in rural areas as those investigated in this work.

All of the applied methods revealed some benefits and constraints. For example, the use of millimeters as a unit for measuring the widening of cracks (Baggio et al. 2009; Burland 1977; Cooper 2008) was found to be better than the use of centimeters (Alexander 1986; Chiocchio et al. 1997). The evaluation of cracks affecting the foundations (Alexander 1986), where possible, was found to be useful, even if very rarely applicable. Almost all of the methods, except those described by Cooper (2008) and Del Soldato et al. (2017), do not consider the importance of the external visibility of the damage in their descriptions. Notably, all of the conducted field campaigns allowed surveying the damage recognizable from the outsides of the structures; almost all the surveyed structures are abandoned or access was denied by the owners. This is a highly relevant issue because, in most cases, the surveyor cannot enter private property, and he/she can assess the damage only from the outside, considering obstacles due to vegetation or gates. This consideration is important during the application of damage classifications to correctly assess their severity, although several of the schemes consider the internal conditions of walls and the degree of pavement inclination. These data are particularity difficult to analyze during preliminary field campaigns or surveys that examine a great number of buildings, except for emergency interventions in restricted areas. Several factors, such as permission to access private properties, fenced areas, and damage hidden by vegetation, have to be considered during the interpretation of building damage maps. The restriction of access to the structure to better investigate the damage situation could be considered a strong limitation of the approach since access to private properties is usually only permitted in case of emergency. Information regarding the crack pattern that affects the internal portion of the structures can improve the damage classifications and, if available, they must be implemented for a better evaluation of the damage.

The evaluation of the damage extent used in the DPC approach (Baggio et al. 2009), despite its apparent lack of simplicity in overcoming the abovementioned difficulties, was demonstrated to be a powerful improvement to better evaluate structures that were differently affected by the damage. Furthermore, the contribution of Cooper's methodology (2008), which also allows assessment of the landslide ground damage, is an important element for providing better descriptions of the landslide-induced damage that affects an area.

All of the benefits and constraints of the five critical analyzed classifications highlighted above should be used to create a new categorization. A novel approach (Del Soldato et al. 2017) was recently published according to the results of the applications of the literature methods in different sites; it maintained a division into two parts of the structure in order to consider the extent of the damage, the width of the cracks in millimeters and the a posteriori classification of affected buildings. The application of the new approach is more focused on the identification and categorization of the severity of the damage that affects the structures, in addition to its extent, considering the difficulties of access to private dwellings during the survey.

The graduation of the damage severity beyond preliminary damage assessments based on external features, can be used for different purposes to improve the understanding of study sites if combined with other information (Infante et al. 2016). Starting with the building and facility categorization, some preventive measures can be improved to avoid the occurrence of further damage in inventoried landslide-prone areas. In areas where possible landslide-induced damages have been recognized, the development of inventory maps and susceptibility maps should be considered to improve the knowledge of the region and to support future planning decisions (Lee et al. 
2003; Di Martire et al. 2012; Guillard and Zezere 2012; Righini et al. 2012; Bianchini et al. 2016). Furthermore, it could be a fundamental support for state legal procedures to assess and reduce the risk of landslides and to increase the resilience of infrastructure through more efficient design. Some examples include updating urban development plans and the obligation to perform geotechnical investigations, including stability analysis, in areas close to buildings damaged by landslides. In the end, to prevent increasing economic losses, some reinforcing measures based on the effects suffered by the structures close to undamaged buildings, e.g., by means of underpinning, should be considered if the structures are located in areas susceptible to landslides. Notably, the area of study is principally rural, and the number of structures and infrastructure is low. The same comparison of different methods conducted in an urbanized area could be more consistent, but it has to be considered that the majority of landslides affect low-urban areas. For this reason, the resulting classification appears to be partially mottled in some cases, whereas for built up areas, the higher number of analyzed structures exhibit a more homogenous classification. This is confirmed by comparing the upper portion of the landslide, where several contractions are present, to the other two exanimated sectors with sparse structures. However, the assessment of damage is independent of the number of the constructions investigated inasmuch any applied method was comparative, but all of the approaches were based on the recognition and analysis of the fractures affecting an edifice.

Corrective measures to restore damaged buildings or to intervene in the activity and the continued evolution of the mass movement are difficult to suggest on the basis of structural damage classifications alone. To pursue these goals, specific structural analyses must be performed, and the improvement described by Cooper (2008) and slightly modified by Del Soldato et al. (2017), which involves categorizing ground surface fractures, in addition to hydrogeological and geomorphological studies, can help to select which measures to adopt and to design better measures after landslides are reactivated.

\section{Conclusions}

Six existing classification methods for landslide-induced damage were presented, compared, and applied to the structures and infrastructure within and close to the Colle Lapponi-Piano Ovetta landslide, in the municipality of Agnone (Molise region, southern Italy). A total number of 30 buildings, two walls, three concrete emplacements, and one electrical mast were investigated in order to classify the severity of damage and to investigate the main benefits and drawbacks of each method by a comparison of the resulting classifications to evaluate their effectiveness in damage assessment. All of the approaches were devised to categorize the level of damage that affects buildings, and despite a similar description of the damage, the involvement of various parameters allows differences in the building classifications.

The differences observed in the resulting maps were discussed based on the characteristics of the approaches as well as the locations and the features of the buildings involved. The most complete and appropriate method for the area of interest was put into practice, even if a better solution might have been to merge different features of existing approaches to homogenize the procedure and to avoid some drawbacks. The difference in classification of structures and infrastructure, as well as in ground fractures for the two more recent approaches, depended on the different parameters used in the classifications once the data were collected. Several considerations that involved the identification of the cracks, the possibility of surveying the damage in private dwellings, and the main information that has to be recorded to achieve good and reliable building classifications, were also discussed in order to extract the limitations and the strengths of each method.

To summarize, the best method for describing the damage level and the real situation of the structures seems to be the recent method developed according to the drawbacks and the benefits of each applied approach. The strength of this approach resulted in the ability to investigate the severity of the cracks, considering several features of previous methods, combined with the extension of the damage and the categorization of the ground fractures that can help define the area involved in the phenomenon. This classification offers a simpler assessment of cracks to be carried out during field surveys based on observable and clear signs as well as taking into account reference widths and an a posteriori classification of the structures by considering the effects of the ruptures.

Ultimately, some considerations of the importance and the usefulness of the building damage data were performed. The information that can be extracted from the resulting maps can assist in managing and planning prevention and remedial actions implemented in different phases and to avoid possible casualties. Some examples include implementing structural and non-structural preventive measures in susceptible areas, monitoring landslide affected areas, providing support to local administrators for planning and promulgating legislative restrictions, and helping private and local authorities renovate damaged structures or evaluate the possibility of moving some structures and facilities.

Acknowledgements The authors thank the University of Florence for funding Dr. Matteo Del Soldato during a $\mathrm{PhD}$ research period in the Department of Civil Engineering at the University of Alicante. The authors also thank the Spanish Ministry of Economy, Industry and 
Competitiveness (MINECO), the State Agency of Research (AEI) and the European Funds for Regional Development (FEDER) under projects TEC2017-85244-C2-1-P and TIN2014-55413-C2-2-P and the Spanish Ministry of Education, Culture and Sport under project PRX17/00439.

Open Access This article is distributed under the terms of the Creative Commons Attribution 4.0 International License (http:// creativecommons.org/licenses/by/4.0/), which permits unrestricted use, distribution, and reproduction in any medium, provided you give appropriate credit to the original author(s) and the source, provide a link to the Creative Commons license, and indicate if changes were made.

\section{References}

Alexander D (1983) The landslide of 13 December 1982 at Ancona Central Italy: report to the Internatinal disaster institute, London

Alexander D (1986) Landslide damage to buildings. Environ Geol Water Sci 8:147-151

Almagià R (1910) Studi geografici sulle frane in Italia. Vol. II. Central and souther Apennine Belt. General conclusions (In Italian). Società Geografica Italiana

Baggio C, Bernardini A, Colozza R, Corazza L (2009) Compilative manual of the 1-level card for damage detection, emergency response and habitability for ordinary buildings in the post-seismic emergency. In: La vulnerabilità degli edifici: valutazione a scala nazionale della vulnerabilità sismica degli edifici ordinari conference, Rome (In Italian)

Bianchini S, Raspini F, Ciampalini A, Lagomarsino D, Bianchi M, Bellotti F, Casagli N (2016) Mapping landslide phenomena in landlocked developing countries by means of satellite remote sensing data: the case of Dilijan (Armenia) area Geomatics, Natural Hazards and Risk:1-17

Boscardin MD, Cording EJ (1989) Building response to excavationinduced settlement. J Geotech Eng 115.1:1-21

Bru G, Herrera G, Tomás R, Duro J, De la Vega R, Mulas J (2013) Control of deformation of buildings affected by subsidence using persistent scatterer interferometry. Struct Infrastruct Eng 9(2):188200

Burland JB (1977) Behavior of foundations and structures on soft ground. In: proc. 9th international conference on soil mechanics foundation engineering, Tokyo, ppp 495-546

Calcaterra D, De Riso R, Evangelista A, Nicotera M, Santo A, Scotto di Santolo (2003) Slope instabilities in the pyroclastic deposits of the Phlegraean district and the carbonate Apennine (Campania, Italy). In: International workshop on occurrence and mechanisms of flows in natural slopes and earthfills, Sorrento, Italy, pp 61-74

Calcaterra D, Di Martire D, Ramondini M, Calò F, Parise M (2008) Geotechnical analysis of a complex slope movement in sedimentary successions of the southern Apennines (Molise, Italy). In: Landslides and engineered slopes. Taylor \& Francis, London, pp 299-305

Calcaterra D, Parise M (2001) The contribution of historical information in the assessment of landslide hazard. In: The use of historical data in natural hazard assessments. Springer, Dordrecht, pp 201-216

Chiocchio C, Iovine G, Parise M (1997) A proposal for surveying and classifying landslide damage to buildings in urban areas. In: Engineering Geology and the Environment, Rotterdam, pp 553-558

Cooper AH (2008) The classification, recording, databasing and use of information about building damage caused by subsidence and landslides. Q J Eng Geol Hydrogeol 41(3):409-424

Crescenzi E, Iovine G, Parise M (1994) Analysis of landslide damage in a village in southern Italy: a preliminary report. Proc. Renc. Int. Jeun. Cher Geol. Appl, Lausanne Suisse, pp 68-72
Cruden DM, Varnes DJ (1996) Landslides: investigation and mitigation. Chapt 3. Landslide types and processes transportation research board special report, $\mathrm{p} 247$

Del Soldato M, Bianchini S, Calcaterra D, De Vita P, Di Martire D, Tomás R, Casagli N (2017) A new approach for landslide-induced damage assessment. Geomatics Nat Hazards Risk:1-14

Di Martire D, De Rosa M, Pesce V, Santangelo MA, Calcaterra D (2012) Landslide hazard and land management in high-density urban areas of Campania region, Italy. Nat Hazards Earth Syst Sci 12(4):905926

Di Martire D, Novellino A, Tessitore S, Ramondini M, Calcaterra D (2013) Application of DInSAR techniques to engineering geology studies in southern Italy. Rendiconti Online della Società Geologica Italiana 24:95-97

Esu F (1977) Behaviour of slopes in structurally complex formations. Int.symp. on the geotechnics of structurally complex formations, Capri, 2:292-304

Filocamo F, Rosskopf CM, Amato V, Cesarano M, Di Paola G (2015) The integrated exploitation of the geological heritage: a proposal of geotourist itineraries in the Alto Molise area (Italy). Rendiconti Online Società Geolologica Italiana 33:44-47. https://doi.org/10. 3301/ROL.2015.11

Freeman TJ, Littlejohn GS, Driscoll RM (1994) Has your house got cracks?: a guide to subsidence and heave of buildings on clay. Telford, London

Godt J, Coe J, Savage W (2000) Relation between cost of damaging landslides and construction age, Alameda County, California, USA, El Niño winter storm season, 1997-98. In: Landslides, proceedings of 8th international symposium on landslides, Cardiff, Wales, pp 26-30

Grünthal G (1998) Conseil de l'Europe

Guadagno F, Palmieri M, Siviero V, Vallario A (1987) The landslide of February 1984 in Fonte Giciatta hamlet in Agnone municipality (Isernia) (In Italian). MemorieSocietà Geolologica Italiana 37:127134

Guillard C, Zezere J (2012) Landslide susceptibility assessment and validation in the framework of municipal planning in Portugal: the case of Loures municipality. Environ Manag 50(4):721-735

Guzzetti F, Cardinali M, Reichenbach P (1994) The AVI Project: A bibliographical and archive inventory of landslides and floods in Italy. Environ Manag 18(4):623-633

Handbook SE (1975) National Coal Board Production Department, London

Hunt RE (2005) Geotechnical engineering investigation handbook. CRC Press, Boca Raton

Infante D, Confuorto P, Di Martire D, Ramondini M, Calcaterra D (2016) Use of DInSAR data for multi-level vulnerability assessment of urban settings affected by slow-moving and intermittent landslides. Proc Eng 158:470-475

Iovine G, Parise M (2002) Classification scheme for detecting landslideinduced damage in urban areas (In Italian). Memorie della Società Geologica Italiana 57(II):595-603

Jennings J, Kerrich J (1962) The heaving of buildings and the associated economic consequences with particular reference to the Orange free state goldfields civil engineer in South Africa. Trans South African Instit Civil Eng 4(11):221-248

Lee E, Moore R (1991) Coastal landslip potential assessment: Isle of Wight Undercliff. Ventnor. Technical Report prepared by Geomorphological Services Ltd for the Department of the Environment, research contract PECD 7/1/272

Lee S, Ryu JH, Min K, Won JS (2003) Landslide susceptibility analysis using GIS and artificial neural network. Earth Surf Process Landf 28(12):1361-1376

MacLeod I, Littlejohn G (1974) Discussion on session 5. In: Conf on settlement of structures, Cambridge. Pentech Press, London, pp 792-795 
Medvedev SV (1965) Engineering seismology

Nawy EG (1968) Crack control in reinforced concrete structures. J Proc 65(10):825-836

Righini G, Pancioli V, Casagli N (2012) Updating landslide inventory maps using Persistent Scatterer Interferometry (PSI). Int J Remote Sens 33(7):2068-2096

Rybár J (1997) Increasing impact of anthropogenic activities upon natural slope stability. In: Proceedings of the international symposium on engineering geology and the environment, June 1997, pp 23-27

Schuster RL (1996) Socioeconomic significance of landslides. Landslides: investigation and mitigation. Transportation Research Board Special Report 247:12-35. National Academy Press, Washington, DC

Schuster RL, Highland L (2001) Socioeconomic and environmental impacts of landslides in the western hemisphere. US Department of the Interior, US Geological Survey, Denver (CO)

Schuster RL, Fleming RW (1986) Economic losses and fatalities due to landslides. Bull Assoc Eng Geol 23(1):11-28
Skempton AW, MacDonald DH (1956) The allowable settlements of buildings. Proc Instit Civil Eng 5:727-768

Tofani V, Segoni S, Agostini A, Catani F, Casagli N (2013) Technical note: use of remote sensing for landslide studies in Europe. Nat Hazards Earth Syst Sci 13:299-309

Van Rooy J (1989) A new proposed classification system for dolomitic areas south of Pretoria. Contrib Eng Geol 1:57-65

Vezzani L, Ghisetti F, Festa A, Follador U (2004) Carta geologica del Molise. SELCA

Wood HO, Neumann F (1931) Modified Mercalli intensity scale of 1931. Seismol Soc Am 21(4):277-283

Wu C, Qiao J (2009) Relationship between landslides and lithology in the Three Gorges Reservoir area based on GIS and information value model. Front Forest Chin 4:165-170

Wu X, Chen X, Zhan FB, Hong S (2015) Global research trends in landslides during 1991-2014: a bibliometric analysis. Landslides 12:1215-1226. https://doi.org/10.1007/s10346-015-0624-z 